\title{
UTILIZATION OF CLASSIFICATION METHODS ON BRIDGE DATABASES IN VIRGINIA
}

\author{
A Thesis \\ Presented to \\ the faculty of the School of Engineering and Applied Science \\ University of Virginia \\ in partial fulfillment \\ of the requirements for the degree
}

Master of Science

by

Christopher Ryan Copeland

December

2014 


\section{APPROVAL SHEET}

The thesis

is submitted in partial fulfillment of the requirements

for the degree of

Master of Science

Christopher Ryan Copeland, Author

The thesis has been read and approved by the examining committee:

Dr. Steven Chase, Advisor

Dr. Jonathan Goodall, Chair

Dr. Michael Brown

Accepted for the School of Engineering and Applied Science:

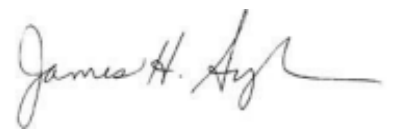

Dean, School of Engineering and Applied Science

December

2014 


\begin{abstract}
The National Bridge Inventory (NBI) was created in 1972, and stores all the information collected from these inspections. It is the largest collection of bridge data in the world and contains detailed information on more than 600,000 United States highway bridges and large culverts. Pontis is a bridge management system and product of the American Association of State Highway and Transportation Officials (AASHTO). Pontis has the capability of storing and analyzing bridge inspection and inventory data, recommending optimal preservation policies, predicting needs and performance measures for bridges, and developing projects to include in an agency's capital plan.

Previously, there has been little analysis performed on the VDOT Pontis and NBI from the perspective of data mining; therefore, the objectives of this study are to consolidate and compile multiple bridge data sets, and to discover previously unknown patterns and trends in the data using data mining and classification methods. The scope of the study includes the application of six classification methods on bridge inspection data to determine when certain bridge types will become structurally deficient. Bridge attributes studied include age, average daily traffic (ADT), truck percentage, district, element condition state, and presence of smart flag elements, and the significance of each is discussed.

Overall, classification methods produced strong results as classifiers of structural deficiency of bridges. The comparison of each classification method using the Orange data mining software is conducted and descriptions and performance of bridges in Virginia have been investigated and are presented in the following sections.
\end{abstract}




\section{ACKNOWLEDGEMENTS}

First, I would like to express my appreciation and gratitude to Dr. Steven Chase. He has been my primary advisor in this investigatory analysis, and, without his support and leadership, the project would have been unstructured. Without him significant conclusions would have been difficult to draw and meaningful recommendations may not have been produced.

I wish to thank my predecessor, Jamie Johnston, who worked alongside Dr. Chase before me, and whose work is cited in this thesis.

I also wish to thank the members of the Virginia Department of Transportation's project advisory group: Mr. Adam Matteo, Mr. Jeffrey Milton, Mr. Rex Pearce, Dr. Michael Brown, Mr. Prasad Nallapaneni, and Mr. Todd Springer. This group is part of the Bridge Information Systems Laboratory for Virginia that informed me and directed me towards the various studies that were completed using the wealth of information compiled in the VDOT Pontis and National Bridge Inventory databases.

Next, I wish to thank the University of Virginia and the Virginia Center for Transportation Innovation and Research for their financial support throughout my research endeavors. I also wish to thank the Civil and Environmental Engineering department for their continued support and access to numerous resources throughout both my Master's and Bachelor's degrees.

Lastly, I wish to thank my parents, family, classmates, and friends who have always been there to support and encourage me from the beginning. 


\section{TABLE OF CONTENTS}

ABSTRACT................................................

ACKNOWLEDGEMENTS.....................................

TABLE OF CONTENTS $. \ldots \ldots \ldots \ldots \ldots \ldots \ldots \ldots \ldots \ldots \ldots \ldots \ldots \ldots \ldots, \ldots \ldots \ldots$

LIST OF TABLES. ....................................vii

LIST OF FIGURES. $\ldots \ldots \ldots \ldots \ldots \ldots \ldots \ldots \ldots \ldots \ldots \ldots \ldots \ldots \ldots$ viii

INTRODUCTION............................................

Project Development.........................................

Motivation...............................................2

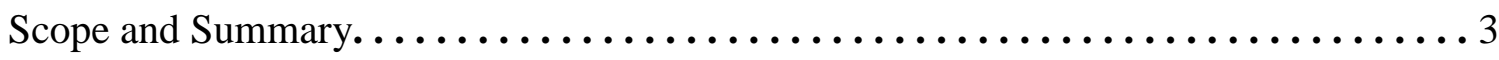

BACKGROUND............................................... 4

Summary NBI and NBIS. $\ldots \ldots \ldots \ldots \ldots \ldots \ldots \ldots \ldots \ldots \ldots \ldots \ldots \ldots \ldots . \ldots \ldots$

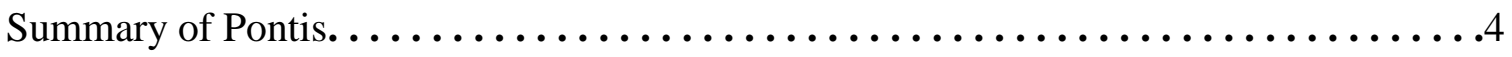

Pontis Element Details and Inspection Guidelines. $\ldots \ldots \ldots \ldots \ldots \ldots \ldots \ldots \ldots \ldots 6$

Data Mining in Bridge Management Systems. $\ldots \ldots \ldots \ldots \ldots \ldots \ldots \ldots \ldots \ldots . \ldots \ldots$

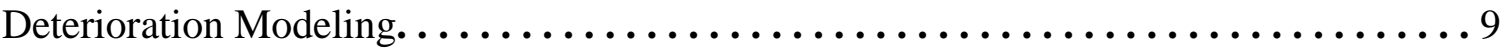

Markov Chain Models.................................9

Regression Models...................................11

Model Findings................................... 11

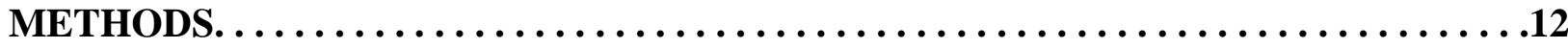

Data Collection........................................... 13

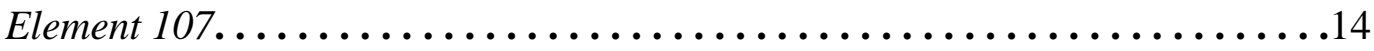

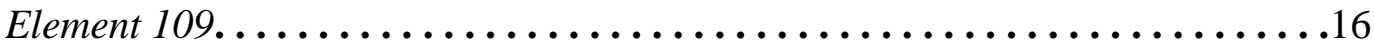


Elements $12,18,22,26 \ldots \ldots \ldots \ldots \ldots \ldots \ldots \ldots \ldots \ldots \ldots \ldots \ldots \ldots$

Classification Methods.....................................

Naïve Bayes..................................... 19

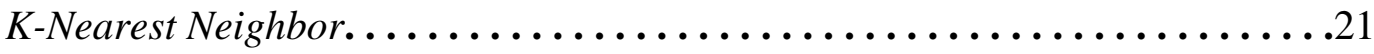

Support Vector Machines...........................22

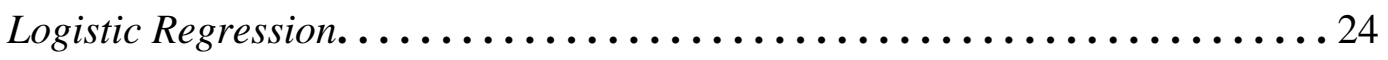

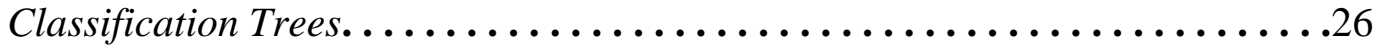

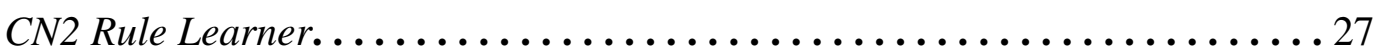

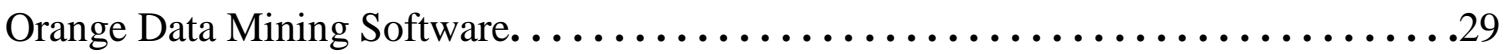

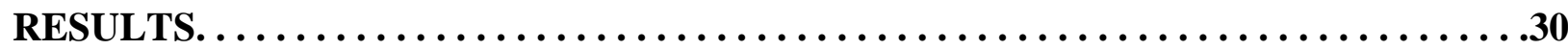

Significant Attributes. ...................................

Selecting a Classification Method............................38

CONCLUSIONS. ................................... 43

Findings. ........................................

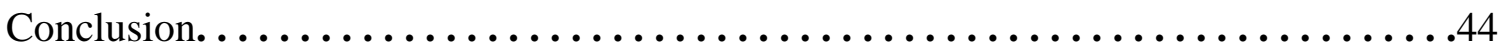

Recommendations................................... 45

REFERENCES. ....................................47

APPENDIX A - ELEMENT CODES AND DESCRIPTIONS. . . . . . . . . . . .53

APPENDIX B - NOMOGRAPHS OF LOGISTIC REGRESSION RESULTS. . . . . . . .57 


\section{LIST OF TABLES}

Table 1: Estimated Service Lives of Selected Elements............................................................ 10

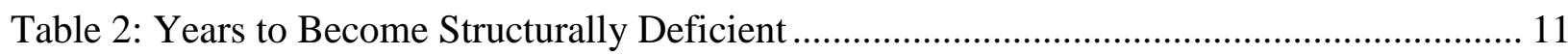

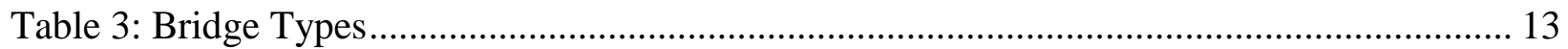

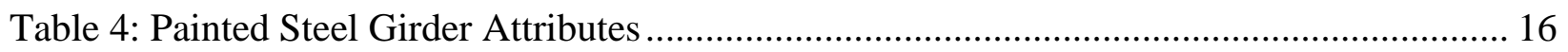

Table 5: Prestressed Concrete Girder Attributes .................................................................. 17

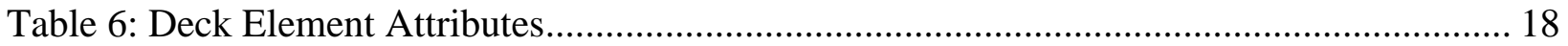

Table 7: Area Under the Receiver Operating Characteristic Curve Results Summary ................ 36 


\section{LIST OF FIGURES}

Figure 1: Separating Hyperplane (MathWorks, Inc., 2014) .................................................. 23

Figure 2: Input Space vs. Feature Space (StatSoft Inc., 2014) ........................................... 23

Figure 3: Linear regression vs Logistic regression (Sayad, 2012)....................................... 25

Figure 4: An example of a data set with three classes labeled 1, 2, and 3 (Loh, 2011)............. 26

Figure 5: Orange Canvas for Bridge Element Data .......................................................... 30

Figure 6: Performance Measures for Painted Steel Girders................................................... 32

Figure 7: Receiver Operating Characteristic Curve for Painted Steel Girders .......................... 33

Figure 8: Receiver Operating Characteristic Curve for Prestressed Concrete Girders ................ 33

Figure 9: Receiver Operating Characteristic Curve for Bare Concrete Deck (Uncoated Rebar) . 34

Figure 10: Receiver Operating Characteristic Curve for Concrete Deck (Thin Overlay) ........... 34

Figure 11: Receiver Operating Characteristic Curve for Concrete Deck (Rigid Overlay) ........... 35

Figure 12: Receiver Operating Characteristic Curve for Bare Concrete Deck (Coated Rebar) ... 35

Figure 13: Attribute Influence on Painted Steel Girders ................................................... 37

Figure 14: Attribute Influence on Prestressed Concrete Girders ........................................... 37

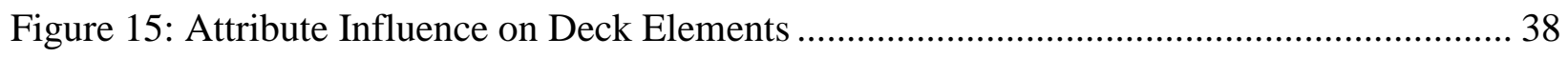

Figure 16: Nomograph of Painted Steel Girders.............................................................. 40

Figure 17: CN2 Rules for Painted Steel Girders............................................................... 41

Figure 18: CN2 Rules for Prestressed Concrete Girders ............................................... 41

Figure 19: CN2 Rules for Bare Concrete Deck (Uncoated Rebar) ......................................... 42

Figure 20: CN2 Rules for Concrete Deck (Thin Overlay) .................................................. 42

Figure 21: CN2 Rules for Concrete Deck (Rigid Overlay) ................................................. 43

Figure 22: CN2 Rules for Bare Concrete Deck (Coated Rebar) ............................................ 43 
Figure B - 1: Nomograph of Prestressed Concrete Girders

Figure B - 2: Nomograph of Bare Concrete Deck (Uncoated Rebar)..................................... 59

Figure B - 3: Nomograph of Concrete Deck (Thin Overlay)............................................. 60

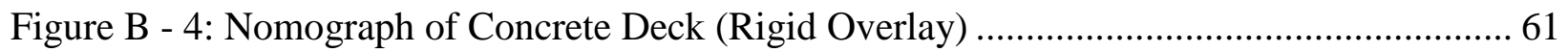

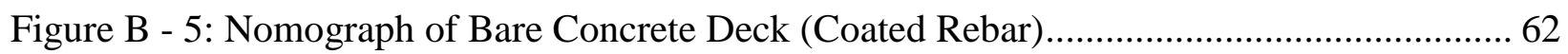




\section{INTRODUCTION}

This introduction is divided into three sections. The first section, Project Development, describes how this study came about, the databases utilized throughout this study, and how the advisory groups were formed as a result of various internal forces in the Virginia Department of Transportation (VDOT). The second section, Motivation, presents the incentive behind investigating statistical classification methods to provide an improved forecasting capability for bridge management systems. The final section, Scope and Summary, outlines the mining process and its results.

\section{Project Development}

As a result of political and public demands for improved bridge management and inspection practices, the National Bridge Inventory (NBI) and Pontis databases were created in 1972 and 1991, respectively. The use of these databases has allowed the Federal Highway Administration (FHWA) to manage the National Bridge Program and provided them the ability to prioritize and allocate funds based on bridge condition. This project performs data mining utilizing various classification methods on these databases to discover trends in bridge performance across the state of Virginia.

The NBI utilizes general condition ratings (GCR) to describe the condition of 5 major bridge components: superstructures, substructures, decks, channels, and culverts. Inspectors are required to give an average rating that provides an overall indication of the general condition of the entire component based on the National Bridge Inspection Standards (NBIS). The Pontis

database breaks down these components further into elements such as steel open girder - painted (element 107) and reinforced concrete pier wall (element 210); a full list of the elements is 
available in Appendix A. Pontis stores condition states for each quantity (each, square feet, linear feet) of the elements that comprise a bridge.

Knowledge Discovery in Databases (KDD) is an idea developed by John Tukey where he states, "exploratory data analysis can never be the whole story, but nothing else can serve as the foundation - as the first step" (Tukey, 1977). The methods of KDD, specifically exploratory data mining, and classification methods are predicated on the fact that the user does not necessarily know what the data will tell him/her when beginning the analysis. Therefore, this project reduced the raw Pontis database and NBI database into useable tables to investigate existing trends in bridge performance.

A Bridge Information Systems Laboratory was created to perform research utilizing exploratory data analysis on legacy bridge data in Virginia. This research includes the research performed and completed by Jamie Johnston, a former Master's student at the University of Virginia. The VDOT Technical Advisory Group (TAG) which helps direct the research undertaken by the laboratory include Mr. Adam Matteo, Mr. Jeffrey Milton, Mr. Rex Pearce, Dr. Michael Brown, and Mr. Prasad Nallapaneni. Mr. Todd Springer joined the group in 2014 when he replaced Mr. Nallapaneni.

\section{Motivation}

This special study was undertaken by the Virginia Center for Transportation Innovation and Research in Charlottesville, Virginia at the request of the VDOT. The lack of a strong bridge maintenance management system in the state of Virginia has been the driving force for this study, and these models were desired and developed to provide statistical support for a planned proposal of a new Interstate bridge maintenance initiative. The objectives of this special study 
were to provide technically sound and statistically valid models to determine the best method for structural integrity classification of Virginia's Interstate bridges.

With previous development of Markov chain and logarithmic regression models to predict deterioration, VDOT's need for further investigation of bridges' structural integrity was improved. Specifically, VDOT desired the ability to predict when bridges would likely become structurally deficient. A structurally deficient bridge has a deck, superstructure, or substructure GCR of 4 or less. Classification methods, a set of data mining techniques, were utilized in this study to determine the best method for forecasting when a bridge will become structurally deficient. They were chosen in order to provide the Department, or anyone, with a statistically significant and easy to understand means of predicting structural deficiency. A number of different classification methods were applied and produced results on bridge data sets derived from the VDOT Pontis and NBI databases.

\section{Scope and Summary}

This project focused on the application of various classification methods and on bridge data in the state of Virginia. The project began with a review of exploratory data mining literature and its application (if any) with bridge inspection data, followed by an evaluation and assessment of previously performed deterioration modeling. Next, the selection and application was conducted of classifications methods that were suitable for the requests made by VDOT. Finally, the performance of the different classification methods were evaluated using multiple performance metrics and ultimately one method was chosen as the best classification method to predict bridge structural deficiency. 


\section{BACKGROUND}

\section{Summary of NBI and NBIS}

The NBIS were created in the early 1970s in response to the 1967 failure of the Silver Bridge between West Virginia and Ohio that resulted in the deaths of 46 people (National Transportation Safety Board, 1970). Since, the FHWA has used bridge inspections to determine states' eligibility for federal funding for bridge programs. The NBI was created in 1972, and stores all the information collected from these inspections (Small, Philbin, Fraher, \& Romack, 1999). In, 1985, the FHWA initiated a two-phase program to evaluate the utility of various management approaches. Phase one assessed existing state bridge management system (BMS) practices and called for an overall synthesis of fundamental elements of a national BMS. Phase two created a computer tool, eventually named Pontis, which each state could implement to manage its own bridge inventory (AASHTO, Pontis User Manual, Pontis Technical Manual, 2005).

\section{Summary of Pontis}

The Pontis is a bridge management system that incorporates a relational database and is a product of the American Association of State Highway and Transportation Officials (AASHTO). Although it has recently been superseded with a newer system, the AASHTO Bridge Manager software, the data utilized for this study was collected using the Pontis system. Pontis has the capability of storing and analyzing bridge inspection and inventory data, recommending optimal preservation policies, predicting needs and, reporting or tracking performance measures for bridges, and aids in developing projects to include in an agency's capital plan (AASHTO, Pontis User Manual, Pontis Technical Manual, 2005); it has been adopted for use by 39 states/territories, 7 other U.S. agencies, and 7 international systems. Pontis is maintained 
through AASHTO’s joint software development program, which allows agencies to both implement and maintain their inventories more cheaply while maintaining an industry standard of best practice that standardizes bridge management on a national level (Robert, Marshall, Shepard, \& Aldayuz, 2003).

The Pontis database for Virginia was created in 1991 in response to the Intermodal Surface Transportation Efficiency Act (ISTEA) which required each state DOT to implement a more functional and detailed bridge management system. It is maintained as a transactional relational database in an Oracle® application that includes records of all bridges across the state since 1995. The NBI inspection program contains ratings of bridges based on bridge components such as deck, superstructure, substructure, channel, and culvert. Under the NBIS, inspectors are required to give an average rating that provides an overall indication of the general condition of the entire component based on NBIS guidelines (Pontis User Manual, 2005).

Because the NBI GCR were determined to be too subjective, Pontis was developed as a more quantitative BMS that looks at structures at the element level. Elements are well-defined subdivisions of bridge components such as girders, joints, and railings, each of which is broken down further by material type. Funding may be more effectively used on maintenance if managers know which specific elements contribute most to deterioration of a bridge.

The NBI database stores condition information on five structural components of a bridge: deck, superstructure, substructure, channel, and culvert. Inspectors assign a condition rating to each of these components on a scale from 9 (perfect) to 1 (severe deterioration). Inspectors using Pontis assign each defined element a condition state on a scale from 1 (perfect) to 3 , 4, or 5 (severe deterioration), depending on the element. Bridge inspectors give and overall average 
condition rating to bridge components using the NBIS and NBI database. However, those using the Pontis break down the condition assessment into the units each element is assigned.

In Pontis, elements are assigned quantitative units. For example, girders are quantified intervals of linear footage, while elements such as bearings are assigned "each", thereby quantifying the total number of bearings on a given bridge. Using more specific inspection records and guidelines enables the user to truly understand how much of certain elements are in or approaching a deteriorated condition state. Pontis also contains "smart flag" elements. These track certain types of deterioration that are specific to certain elements and are not listed in the structural element condition state definitions. This study investigated the effects of certain smart flags, such as impact damage and steel fatigue, because they have a serious impact on bridge condition and do not necessarily exhibit a logical pattern of deterioration.

\section{Pontis Element Details and Inspection Guidelines}

The Virginia Pontis Element Data Collection Manual defines 111 elements and their associated condition states and definitions for bridges in the state of Virginia. The Commonly Recognized (CoRe) elements make up 100 of these elements and have identical definitions between agencies in order to facilitate more uniform data collection and analysis on the national level. The other eleven elements were uniquely defined by VDOT based on particular guidelines defined in the Pontis that allow states to add additional elements to track their condition. Additionally, there are nineteen smart flags recorded in Virginia, eight of which are CoRe while the remaining eleven are uniquely defined by the Virginia DOT. The full list of the 111 elements and nineteen smart flags is presented in Appendix A.

The Pontis Element Data Collection Manual defines the condition state guidelines for the Pontis element-level inspection reporting (VDOT, 2007). Additional guidelines for 
responsibility of inspection of state and federal bridges are presented in The National Bridge Inspection Standards (FHWA, 1994). The specific procedures for inspection and reporting are outlined in the AASHTO Maintenance Manual for Roadways and Bridges (AASHTO, 2007), the AASHTO Manual for Bridge Evaluation (AASHTO, 2011), the Recording and Coding Guide (FHWA, 1995), and the Bridge Inspector's Reference Manual (Ryan, Hartle, Mann, \& Danovich, 2006). These documents were used as references in this study for their detailed explanation of the different bridge members and their definitions of the associated condition ratings for the superstructure, substructure, and deck.

\section{Data Mining in Bridge Management Systems}

Data mining is the analysis of large observational data sets to find unsuspected relationships and to summarize the data in novel ways that are both understandable and useful to the data owner. The application of data mining has become more important with the growth of huge databases as a result of progress in digital data acquisition and storage technology (Hand, Mannila, \& Smyth, 2001). The Pontis database and National Bridge Inventory are two of the largest collections of bridge data and there has been very little analysis performed on each from the perspective of data mining.

Transition probabilities and deterioration modeling have been used before to find trends in both of these bridge databases. Samer Madanat refers to Markovian transition probabilities as the expected-value method of condition ratings observed over time. This method contains three important steps: structures are classified into groups containing the same attributes; a deterioration model with condition rating, as the dependent variable, and age, as the independent variable, is estimated; and, a transition probability is estimated (Madanat, Mishalani, \& Wan Ibrahim, 1995). 
A few years later, Markovian models were used in the state of California to employ a network optimization model for preservation. Cost/benefit models were produced to maintain a program that is optimized with budget constraints that generates project alternatives by combining preservation and improvement needs on each bridge (Thompson, Small, Johnson, \& Marshall, 1998). Another study, conducted by Richard Shepard and Michael Johnson (an author to the previous study) in California, takes element-level inspection data from Pontis to determine a bridge's overall economic worth. Then, a single number assessment is determined and The Health Index was created. This index is used to ascertain the structural quality of a bridge and have the ability to make objective comparisons to other bridges (Shepard \& Johnson, 2001).

Traditional statistical methods cannot be easily applied to databases with the magnitude of Pontis and NBI and practical hypotheses and significant results may not be derived from these methods. Data mining using classification methods has not been at the forefront of bridge management research, and most bridge analyses rely on the development of deterioration curves. For example, a study in the state of Illinois (Bolukbasi, Mohammadi, \& Arditi, 2004) uses two means to construct deterioration curves of state and interstate bridges. The first applies an adjustment in condition ratings based on the notion that unless there is evidence of improvement work, the condition rating cannot be larger than previous ratings, and the second is based on the duration between consecutive inspections.

Few studies have been conducted like the ones above, yet further knowledge of the future condition state of our bridges is highly desired. Therefore, the objectives of this study are to consolidate and compile multiple bridge data sets, and to discover previously unknown patterns and trends in the data using data mining and classification methods. 


\section{Deterioration Modeling}

Earlier work in Virginia focused on deterioration modelling and is documented in the Exploratory Investigation of Legacy Bridge Databases in Virginia (Johnston, 2013). Initially, two different approaches were taken to develop deterioration models. The first approach used the Pontis element level data and fit Markov Chain models to predict deterioration. The second approach used NBI data and fit logarithmic regression models to predict deterioration for these same bridges. The available data was reviewed and records with inconsistent quantities, too few bridges and unexplained condition improvement were excluded from the study. The bridges with the most prevalent superstructure and deck elements were investigated with ages ranging from 65 years to brand new.

\section{Markov Chain Models}

For the Markov Chain model, the proportion of bridges in each of the defined condition states for each element was determined for each age bin. This data was used to fit a Markov Chain deterioration model for each of the six elements identified. It is assumed that the proportion within each condition state will change as the element deteriorates. This change in proportion is considered as a change in the probability that the condition state will take on one of the defined values. This transition was modeled with a Markov Chain, where the probability of the condition state remaining unchanged and the probability of the condition state becoming lower (worsening) is assumed to remain constant for each transition (assumed to occur annually). Using this simple model, the condition state transition probabilities, which resulted in the minimum squared error between a simulation and the observed data, were determined with an Excel worksheet. 
Virginia DOT's Technical Advisory Group (TAG) reviewed the Markov model results, and established thresholds which were considered suitable for defining when a particular element has reached the end of its service life. Different percentages for each of the different condition states were defined based upon the TAG's judgment and the condition state definitions. The thresholds and the number of years it would take for a particular element to reach a threshold value, based upon the Markov Chain models are presented in Table 1.

\begin{tabular}{|c|c|c|c|c|c|c|c|}
\hline \multicolumn{7}{|c|}{ Years to Reach Threshold Values } \\
\hline $\begin{array}{c}\text { Condition } \\
\text { State }\end{array}$ & $\begin{array}{c}\text { Superstructure } \\
\text { Superstructure }\end{array}$ & Deck 12 & Deck 18 & Deck 22 & Deck 26 & Threshold \\
\hline 1 & 107 & 109 & & & & & \\
\hline 1 & 51 & $>65$ & 23 & 15 & 23 & 36 & $50 \%$ \\
\hline 2 & 22 & $>65$ & 10 & 7 & 10 & 16 & $25 \%$ \\
\hline 3 & 33 & $>65$ & 31 & 40 & 45 & 40 & $10 \%$ \\
\hline 4 & 43 & $>65$ & 37 & 39 & 52 & 33 & $5 \%$ \\
\hline 5 & 42 & N.A. & 21 & 42 & 38 & $>65$ & $1 \%$ \\
\hline
\end{tabular}

Table 1: Estimated Service Lives of Selected Elements

The TAG decided that a particular element would need to be replaced if 50 percent of the total quantity of an element was worse than condition state 1 , or if 25 percent was in condition state 2 or worse, or if 10 percent was in condition state 3 or worse, or if 5 percent was in condition state 4 or worse, or if 1 percent was in condition state 5 .

While, considered useful by the TAG, the Markov Chain models did not immediately provide an estimate of structural deficiency. They also did not provide any indication of uncertainty and modeling error. Another set of models were developed, based upon regression to provide further assistance to the TAG. 


\section{$\underline{\text { Regression Models }}$}

The second modeling methodology utilized was to fit a regression model to the NBI general condition ratings for superstructure and deck for the sample bridges. Along with VDOT's desire to be able to estimate the time it would take for a bridge to become structurally deficient, there was a desire to obtain error bounds estimates as well.

For each group of bridges in the sample, using the same age bins as previously, the minimum, maximum and first, second and third quartiles of the NBI general condition rating (GCR) for superstructure or deck were determined as appropriate. There were many age bins where the number of bridges was below 5, and, consequently, the quartile estimates were not reliable. The age bins with a sufficient number of bridges were retained and a weighted linear least squares regression model was used to fit the median GCR to the log-transformed age. A similar procedure was used to define the curves for the first and third quartile estimates.

Based upon the regression models, an estimate of the time it would take for the GCR to become 4 can be estimated. These estimates are presented in Table 2 below.

\begin{tabular}{|c|c|c|c|c|c|c|}
\hline \multicolumn{7}{|c|}{ Time to Become Structurally Deficient } \\
\hline Element & $\begin{array}{c}\text { Superstructure } \\
107\end{array}$ & $\begin{array}{c}\text { Superstructure } \\
109\end{array}$ & Deck 12 & Deck 18 & Deck 22 & Deck 26 \\
\hline Years to SD & $>100$ & $>100$ & 100 & 85 & 75 & $>100$ \\
\hline
\end{tabular}

Table 2: Years to Become Structurally Deficient

\section{Modeling Findings}

Several models were developed which provided the Virginia Department of Transportation forecasting capabilities. These assisted them in developing a new bridge maintenance initiative for Interstate bridges in Virginia. Overall, reasonable deterioration 
models were developed for the most significant elements present in the Interstate Highway Bridge population in Virginia.

However, by request of VDOT's TAG, further examination was desired for the following reasons. The age of the bridges studied was limited to sixty five years or less. Therefore, any extrapolation beyond this limit must be regarded with skepticism. Also, the data had many instances of missing values. This reflects bridge engineering practice and policies over the sixty five years examined and the resulting models should be used with this knowledge.

Furthermore, in the process, it was found that there is a significant difference between the forecasts developed using element level data from the VDOT Pontis database and models developed using general condition ratings from the NBI database. Therefore, the relationship between the element condition state data and general condition ratings for each of the six elements was examined more closely across the state of Virginia.

\section{METHODS}

This section is divided into three sub-sections. The first sub-section, Data Collection, describes how each of the six bridge element data sets were compiled and organized. The second sub-section, Classification Methods, provides an explanation of each of the six classification methods used to investigate the bridge data. The final sub-section, Orange Software, describes the Orange data mining software system utilized in this research and its capabilities and how each classification method is implemented within the program.

The purpose of this study was to use the VDOT Pontis database and NBI database to investigate classification methods and forecast when a bridge will become structurally deficient. As defined by FHWA, a structurally deficient bridge is one with a bridge deck, superstructure, or 
substructure reaching a rating of 4 or less. This does not imply that the bridge is unsafe or may collapse; simply that it must be monitored, inspected, and maintained, and that it may be restricted to weight limits, closed to traffic, and/or require significant rehabilitation. The scope of the modelling was limited to bridges in Virginia on the Interstate system.

Bridge data sets were compiled for six different elements. These data sets were comprised of attributes including age, the district it is located in, average daily traffic (ADT), truck percentage, a condition state profile (defined below for each element), and applicable smart flags that may be present. A current classification of each bridge's general condition rating (GCR) from the NBI was also included in the data sets to be compared with predicted classification values. The superstructure GCRs were compared for the substructure elements, while the deck GCRs were compared for the deck elements.

\section{Data Collection}

Bridge data sets were compiled based on element type, and the same six elements were investigated for this study as previously done for the deterioration modelling.

\begin{tabular}{|l|c|}
\hline \multicolumn{1}{|c|}{ Bridge Type } & Element \# \\
\hline Painted Steel Girders & 107 \\
\hline Prestressed Concrete Girders & 109 \\
\hline Bare concrete decks with uncoated rebar & 12 \\
\hline Concrete deck with thin overlay & 18 \\
\hline Concrete deck with rigid overlay & 22 \\
\hline Bare concrete deck with coated bars & 26 \\
\hline
\end{tabular}

Table 3: Bridge Types

All Interstate bridges containing painted steel girders, element 107, (and each additional element) were sorted by bridge key, a unique identification number assigned to each bridge, and inspection date. The inspection records contain element condition states (1-5 rating) reported by inspectors over the years. In most cases, inspections on each bridge were performed every two 
years; however, some bridges had more frequent inspections while some inspections were greater than five years apart. The scope of this study focused on the two most recent inspections for each bridge. The data collection process for each element is provided below and presents the element condition state descriptions as defined by the VDOT Pontis Manual.

\section{Element 107}

As defined in VDOT's Element Level Coding Guide, painted steel superstructures include two girder systems as well as rolled beams on multiple spans. The data set was compiled of bridges in which the structure carried only Interstate routes; it consisted of a total of 546 bridges. In order to facilitate classification, "condition state profiles" were created. A letter grade was assigned based on the certain percentages in each condition state. An "A" was given to inspections containing the entire quantity in condition state 1 , a " $\mathrm{B}$ " to those having partial quantities in condition state 2 , a "C" to those having partial quantities in condition state 3 , and a " $\mathrm{D}$ " to those having any quantity in condition state 4 or worse.

Element 107 condition state descriptions:

1 There is no evidence of active corrosion and the coating system is sound and functioning as intended.

For coated cables, the protective coating is sound and functioning as intended, For coated cables, the strand and anchor sockets show no signs of distress.

2 There is little or no active corrosion.

Surface or freckled rust has formed or is forming.

The coating system may be chalking, peeling, curling or showing other early evidence of coating system distress but there is no exposure of metal.

For coated cables, the strand and anchor sockets show no signs of distress.

3 Surface or freckled rust is prevalent.

There may be exposed metal but there is no measurable section loss caused by active corrosion.

For coated cables, protective system is no longer effective.

For coated cables, the strand and anchor sockets show no signs of distress.

4 Corrosion is present.

Section loss due to active corrosion does not warrant structural analysis.

For coated cables, the cable banding, if any, may show some loosening or slippage.

For coated cables, the cable anchor devices may be loosening.

Also code Element 363 (Section Loss). 
Corrosion is advanced.

Section loss due to active corrosion is sufficient to warrant structural analysis.

For coated cables, the cable strands or wires may be broken or severely abraded.

For coated cables, the anchors may show signs of slippage.

Also code Element 363 (Section Loss).

This type of structure warranted the investigation of certain smart flag elements. Therefore, steel fatigue, traffic impact damage, and section loss were also taken into account. Letter grades were assigned for smart flag elements which contain quantities in entire condition states. An "A" was given in the presence of no smart flags, a "B" to those in condition state 1 , a " $\mathrm{C}$ " to those in condition state 2 , and a " $\mathrm{D}$ " to those in condition state 3 . The attributes investigated for element 107 are listed in Table 4.

Steel Fatigue (smart flag 356) condition state descriptions:

$\mathrm{N} \quad$ No presence of fatigue damage.

1 Fatigue damage to the bridge has been repaired or arrested.

The bridge may still be fatigue prone.

2 Fatigue damage exists which is not arrested.

3 Fatigue damage exists which is sufficient to warrant structural analysis.

Traffic Impact Damage (smart flag 362) condition state descriptions:

$\mathrm{N} \quad$ No presence of impact damage.

1 Impact damage has occurred and has been repaired.

Prestressing system is covered by patch concrete.

Steel has been straightened or repaired.

2 Impact damage has occurred.

Prestressing system is exposed, but is not impaired.

Steel condition does not threaten the ability of the bridge to function as intended.

3 Impact damage has occurred and strength of the member is impaired.

Impact damage is sufficient to warrant structural analysis.

Section Loss (smart flag 363) condition state descriptions:

N No presence of section loss.

1 Section loss has been repaired or cleaned and coated over.

2 Section loss exists and has not been repaired or coated over. Structural analysis is not yet warranted.

3 Section loss exists which is sufficient to warrant structural analysis or an analysis has determined that the ability of the bridge to function as intended has not been affected.

4 Section loss has affected the load carrying capacity or the ability of the bridge to function as intended. 


\begin{tabular}{|c|}
\hline Painted Steel Girder Attributes \\
\hline Age \\
\hline District \\
\hline Average Daily Traffic (ADT) \\
\hline Truck Percentage \\
\hline Condition State Profile \\
\hline Steel Fatigue - SF 356 \\
\hline Traffic Impact Damage - SF 362 \\
\hline Section Loss - SF 363 \\
\hline
\end{tabular}

Table 4: Painted Steel Girder Attributes

\section{Element 109}

The prestressed concrete girder data set was expanded from Interstate bridges to all state maintained bridges in Virginia because there were too few structurally deficient bridges in the Interstate sample. This increased the sample size to allow for stronger model development; it consisted of a total of 473 bridges. Similar to element 107, the inspection quantities were in multiple condition states, and "condition state profiles" were also created based on the same criteria. These profiles also ranged from A-D.

Element 109 condition state descriptions:

1 Little or no deterioration. There may be discoloration, efflorescence, and/or superficial cracking but without effect on strength and/or affecting the ability of the element to function as intended.

2 Minor deterioration.

Hairline cracks \& spalls may be present and there may be exposed reinforcing with no evidence of corrosion.

There is no exposure of the prestressed system.

3 Moderate deterioration.

Some delaminations and/or spalls may be present.

There may be minor exposure but no deterioration of the prestressed system. Corrosion of non-prestressed reinforcement may be present but loss of section is incidental and does not warrant structural analysis.

$4 \quad$ Advanced deterioration.

Delaminations, spalls and corrosion of non-prestressed reinforcement are prevalent.

There may also be exposure and deterioration of the prestressed system (manifested by loss of bond, broken strands or wire, failed anchorages, etc.). There is sufficient concern to warrant structural analysis.

The prestressed concrete structure only warranted the investigation of one smart flag: traffic impact damage. The same criteria and smart flag mapping were used as with element 107. The attributes investigated for element 109 are listed in Table 5. 


\begin{tabular}{|c|}
\hline Prestressed Concrete Girder Attributes \\
\hline Age \\
\hline District \\
\hline Average Daily Traffic (ADT) \\
\hline Truck Percentage \\
\hline Condition State Profile \\
\hline Traffic Impact Damage - SF 362 \\
\hline
\end{tabular}

Table 5: Prestressed Concrete Girder Attributes

\section{Elements $12,18,22$, and 26}

All decks in this study were reinforced concrete decks. Similar to element 109, the scope of each of the deck data sets was expanded to all state maintained bridges in Virginia. The data sets of elements 12,18, 22, and 26 consisted of 1,338, 787, 403, and 1,575 bridges, respectively. The inspection records of the deck elements are coded as "each;" therefore, condition state profiles weren't necessary, and condition states were directly mapped. For example, condition state 1 received an "A", condition state 2 received a "B", and so forth.

Concrete Deck condition state descriptions:

1 This element exhibits no patched areas and/or deficiencies such as spalling, delamination, etc.

2 Patched areas, spalling/delamination and/or potholes exist. Their combined area is $10 \%$ or less of the total deck area.

3 Patched areas, spalling/delamination and/or potholes exist. Their combined area is more than $10 \%$ but $25 \%$ or less of the total deck area.

4 Patched areas, spalling/delamination and/or potholes exist. Their combined area is more than $25 \%$ but less than $50 \%$ of the total deck area.

5 Patched areas, spalling/delamination and/or potholes exist. Their combined area is $50 \%$ or more of the total deck area.

The reinforced concrete decks warranted the investigation of two smart flag elements. Therefore, deck cracking and soffit of concrete decks/slabs were taken into account. The same smart flag mapping was performed for the deck element as above, and the attributes investigated for these elements are listed in Table 6.

Deck Cracking (smart flag 358) condition state descriptions:

$\mathrm{N} \quad$ No presence of deck cracking

1 The surface of the deck is cracked, but the cracks are either filled/sealed or insignificant in size and density (cracks less than 1/16 inch in width and spaced greater than 10 feet apart).

2 Unsealed cracks exist which are of moderate size OR density (cracks greater than or equal to 1/16 inch and less than 3/16 inch in width OR where cracks are spaced 5 feet to 10 feet apart). 
3 Unsealed cracks exist in the deck that are of moderate size AND density (cracks greater than or equal to 1/16 inch and less than 3/16 inch in width AND where cracks are spaced 5 feet to 10 feet apart).

$4 \quad$ Unsealed cracks exist in the deck that are of severe size AND/OR density (cracks greater than 3/16 inch in width AND/OR are spaced less than 5 feet apart).

Soffit of Concrete Decks/Slabs (smart flag 359) condition state descriptions:

$\mathrm{N} \quad$ No presence of concrete soffit

1 There are few symptoms of distress and any cracking or efflorescence is less than $2 \%$ of the total underside area.

2 Cracking and/or efflorescence is light any the combined distressed area is $2 \%$ to $10 \%$ of the soffit.

3 Moderate efflorescence and/or cracking (cracks greater than or equal to 1/16 inch and less than 3/16 inch in width OR where cracks are spaced 5 feet to 10 feet apart) and the combined distressed area is greater than $10 \%$ but $25 \%$ or less of the soffit.

4 Light to moderate rust staining and/or delamination/spalling and heavy cracking (cracks greater than or equal to 1/16 inch and less than 3/16 inch in width AND where cracks are spaced 5 feet to 10 feet apart) and/or efflorescence and the combined distressed area is more than $25 \%$ but less than $50 \%$ of the soffit.

5 Heavy to severe rust staining and/or delamination/spalling and severe cracking (cracks greater than 3/16 inch in width AND/OR are spaced less than 5 feet apart) and/or efflorescence and the combined distressed area is $50 \%$ or more of the soffit.

\begin{tabular}{|c|}
\hline Deck Element Attributes \\
\hline Age \\
\hline District \\
\hline Average Daily Traffic (ADT) \\
\hline Truck Percentage \\
\hline Condition State Profile \\
\hline Deck Cracking - SF 358 \\
\hline Soffit of Concrete Decks/Slabs - SF 359 \\
\hline
\end{tabular}

Table 6: Deck Element Attributes

\section{Classification Methods}

Multiple classification methods were investigated and utilized in this study to determine the best method for forecasting when a bridge will become structurally deficient. Each bridge data set was used as an input for six different classification methods: naïve Bayes, $k$-nearest neighbor, support vector machine, logistic regression, classification tree, and the CN2 rule 
learner. The classification methods developed and produced "classifiers" based on the attributes for each bridge. These attributes were used to determine a prediction of "structurally deficient" or "not structurally deficient" for each bridge. Comparisons of these predictions were made to those of the current classifications.

Each classification method produces a classification model, "classifier", providing a prediction of structural deficiency. In pattern recognition and statistical classification, a classifier is a distinct algorithm or precise function that maps input data into a category (Jain, Duin, \& Mao, 2000).

\section{$\underline{\text { Naïve Bayes }}$}

A naïve Bayes classifier is a probabilistic classifier based on the application of Bayesian statistics and the assumption of independent features. This means that the classifier assumes that each individual feature is unrelated to the others. Naïve Bayes has been used for pattern recognition and information retrieval for almost forty years (Lewis, 1998). Although independence is commonly a poor assumption, the naïve Bayes classifier has advantages that allow it to compete well against more sophisticated classifiers. Its ability to undertake a high dimensionality of inputs and handle an arbitrary number of independent variables regardless of type (e.g., categorical or continuous) are two of its major advantages (Rish, 2001).

The basic theory of naïve Bayes classifier is presented. First, consider how to design a learning (or training) algorithm based on Bayes rule in which an unknown target function $f: X \rightarrow$ $Y$, equivalently $P(Y \mid X)$, or the probability of $Y$ given a known $X$ is approximated. In order to reduce the complexity of the Bayesian classifiers, the assumption of conditional independence is used which dramatically reduces the number of parameters. For example, given random 
variables $X, Y$ and $Z$, variable $X$ is conditionally independent of $Y$ given $Z$, if and only if the probability distribution governing $X$ is independent of the value of $Y$ given $Z$; that is:

$$
(\forall i, j, k) P\left(X=x_{i} \mid Y=y_{j}, Z=z_{k}\right)=P\left(X=x_{i} \mid Z=z_{k}\right)
$$

Eq. 1

To describe conditionality further, consider the current weather: Rain, Thunder, and Lightning. The presence of Thunder, in this example, is independent of Rain given the presence of Lightning. We know that Lightning causes Thunder, and once we know whether or not there is currently Lightning, no additional information about Thunder is provided by the value of Rain. Certainly there is a clear dependence of Thunder on Rain in general; however, there is no conditional dependence after the value of Lightning is known (Mitchell, 2010).

The Bayes rule, defined as $P(Y \mid X)$, contains the attributes $X_{1} \ldots X_{n}$ that are all independent of one another. This assumption drastically simplifies the representation of $P(Y \mid X)$ and makes the problem of estimating it from the training algorithm easier. Consider the simple case where $\boldsymbol{X}=\left\{X_{1}, X_{2}, X_{3}\right\}$. In this case:

$$
\begin{aligned}
P\left(Y / X_{1} \ldots X_{3}\right) & =P(Y) P\left(X_{1} \ldots X_{3} / Y\right) \\
& =P(Y) P\left(X_{1} / Y\right) P\left(X_{2} \ldots X_{3} / Y, X_{1}\right) \\
& =P(Y) P\left(X_{1} / Y\right) P\left(X_{2} / Y, X_{1}\right) P\left(X_{3} / Y, X_{1}, X_{2}\right)
\end{aligned}
$$

Since Bayes rule assumes conditional independence, assume each attribute $X_{i}$ is conditionally independent to the next $X_{j}$ for $j \neq i$ given the category $Y$. Therefore the joint model may be expressed as: 


$$
\begin{aligned}
P\left(X_{1} \ldots X_{3} / Y\right) & =P\left(Y, X_{1}, \ldots, X_{3}\right) \\
& =P(Y) P\left(X_{1} / Y\right) P\left(X_{2} / Y\right) P\left(X_{3} / Y\right)
\end{aligned}
$$

Eq. 3

This series of equations may be expressed more generally as:

$$
P\left(X_{1} \ldots X_{n} \mid Y\right)=P(Y) \prod_{i=1}^{n} P\left(X_{i} \mid Y\right)
$$

Eq. 4

\section{$\underline{K \text {-Nearest Neighbor }}$}

The $k$-nearest neighbor $(\mathrm{kNN})$ rule is a non-parametric technique, that is it does not assume that the model has a fixed size and that it can change with the complexity of the data, used in statistical estimation and pattern recognition by an algorithm that stores all available cases and classifies new cases based on similarity measures or distance functions (Weinberger, Blitzer, \& Saul, 2005). Unlike other common classifiers, the kNN rule does not build a classifier in advance; each new sample finds the $k$ neighbors nearest it from training space based on the attributes and a distance metric (Khan, Ding, \& Perrizo, 2002).

Before determining the proper distance metric, the first step in $k$-nearest neighbor classification is choosing an appropriate $k$ value. The nature and size of the data ultimately determines the optimal value for $k$. Using a $k$ value that is too large may include data points that are not as similar; however, using a small $k$ value may exclude some significant data points. After trial and error testing, a $k$ value of 5 was chosen for this study as it produced the strongest results and is the most appropriate for the sample size while maintaining significant results.

Next, the appropriate distance metric is chosen. The performance of $k$-nearest neighbor classification is highly dependent on the distance metric chosen to identify nearest neighbors. Distance metrics for $\mathrm{kNN}$ classification are tailored to specific problems and change when the 
desired resultant class changes. For example, the optimal distance metric used to investigate gender identification is most likely not the same distance metric used to study face recognition. There are four main distance metrics:

$\begin{array}{ll}\text { Euclidean: } & d(x, y)=\sqrt{\sum_{i=1}^{n}\left(x_{i}-y_{i}\right)^{2}} \\ \text { Hamming: } & d(x, y)=\sum_{i=1}^{n}\left(x_{i} \neq x_{j}\right) \\ \text { Manhattan: } & d(x, y)=\sum_{i=1}^{n}\left|x_{i}-y_{i}\right| \\ \text { Maximal: } & d(x, y)=\max \left(\left|x_{i}-y_{i}\right|\right)\end{array}$

The Hamming distance is not suitable for continuous data and utilizes the number of attributes in which two examples differ. The Manhattan distance calculates the sum of absolute differences for all attributes while Maximal distance calculates the maximal difference between attributes. The Euclidean distance metric is used in the most simple kNN classifications and was selected for this study because of its simplicity under the assumption of an absence of prior knowledge about the data sets.

\section{$\underline{\text { Support Vector Machines }}$}

Support vector machines (SVMs) classify data into two classes by finding the best decision plane (or hyperplane) that separates all data points between a set of objects having different class memberships. SVM is known to be especially efficient in handling large classification problems due to its ability to manage very large feature spaces (Widodo \& Yang, 2007).

The best plane for SVMs is the one with the largest margin, or maximum width of margins away from the hyperplane, between the two classes (MathWorks, Inc., 2014). Figure 1 depicts a schematic example of a linear hyperplane between two classes: positive and negative 
data points. The support vectors are those data points closest to the hyperplane that lie directly on the margin boundary.

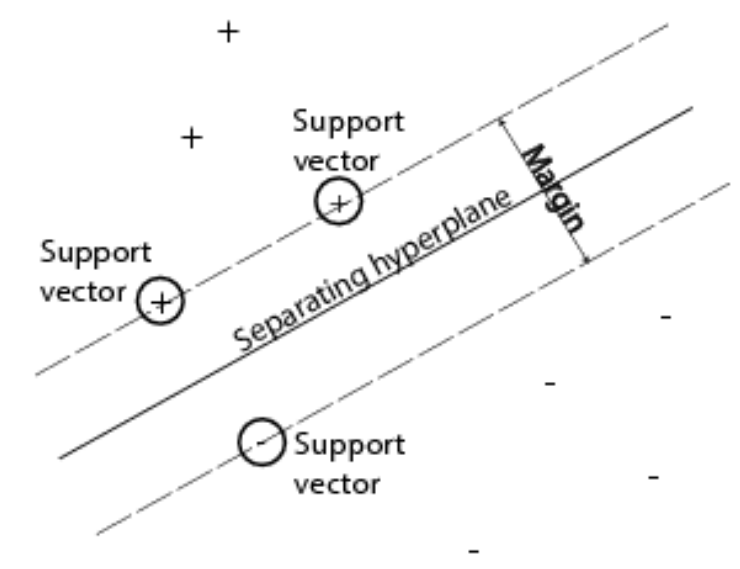

Figure 1: Separating Hyperplane (MathWorks, Inc., 2014)

Most cases, however, do not yield a perfectly linear relationship. Therefore, a set of mathematical functions, known as kernels, are used on input space objects to rearrange and map them into a feature space (StatSoft Inc., 2014). The mapping transformation is performed to utilize a linear separating hyperplane rather than a more complex curved hyperplane relationship. Figure 2 shows how mapping is used to transform input space to feature space. The test object (white circle) is classified correctly based on the proper mapping of the training objects (red and green circles).

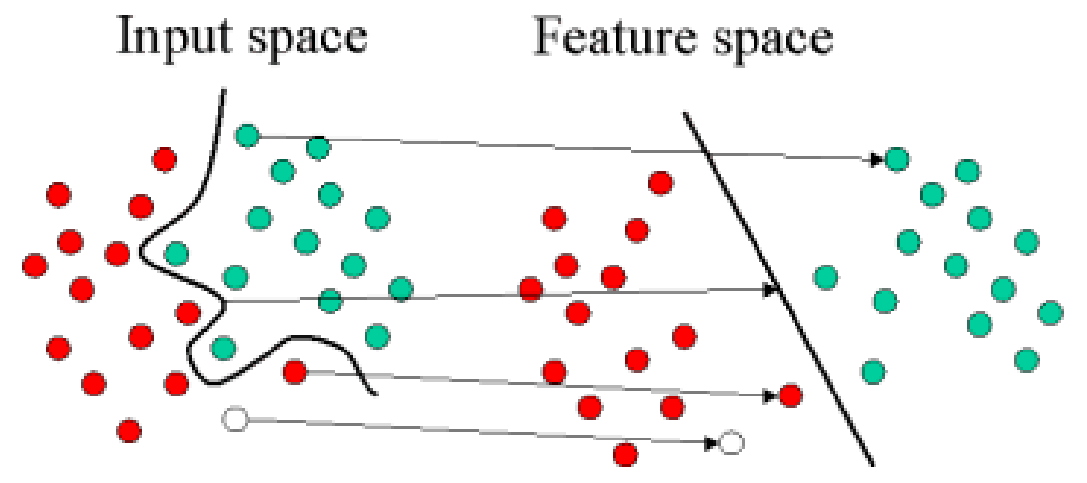

Figure 2: Input Space vs. Feature Space (StatSoft Inc., 2014) 
The four basic kernel functions are:

Linear:

Polynomial:

Radial Basis Function (RBF):

Sigmoid:

$$
K\left(x_{i}, x_{j}\right)=x_{i} x_{j}
$$$$
K\left(x_{i}, x_{j}\right)=\left(\gamma x_{i} x_{j}+c\right)^{d}
$$$$
K\left(x_{i}, x_{j}\right)=e^{\left(-\gamma\left|x_{i} x_{j}\right|^{2}\right)}, \gamma>0
$$$$
K\left(x_{i}, x_{j}\right)=\tanh \left(\gamma x_{i} x_{j}+c\right)
$$

where, $\gamma, c$, and $d$ are kernel parameters.

The radial basis function was the chosen kernel for this study. It, unlike linear relationship kernels, handles cases in which the relationship between attribute and class is nonlinear (Hsu, Chang, \& Lin, 2003), much like the nature of bridge inspection data. Additionally, the decision to utilize the RBF kernel was reached because the number of parameters influences the complexity of model selection; RBF uses fewer parameters than the polynomial and sigmoid parameters. The gamma, $\gamma$, parameter used in RBF is recommended to be $1 / k$, where $k$ is the number of attributes used for each data set.

\section{$\underline{\text { Logistic Regression }}$}

Logistic regression is another classification method and statistical model that utilizes a series of predictor variables that influence the probability of an outcome. The difference between it and ordinary linear regression is that logistic regression contains a value predictor that is binary and dichotomous. Therefore, in order for a logistic regression to be applied, modifications to the equation are made to express the outputs in terms of probability:

$$
\log \left(\frac{p}{1-p}\right)=\beta_{o}+\beta_{1} X_{1}+\cdots+\beta_{i} X_{i}
$$


where $p$ is the probability of the outcome of interest, $\beta_{\mathrm{i}}$ coefficients are associated with each variable and calculated to minimize error, and $X_{i}$ are the values of the potential predictor variables, such as age of the bridge, its location, etc. (Tu, 1996). Figure 3 below depicts the difference between linear regression and logistic regression.

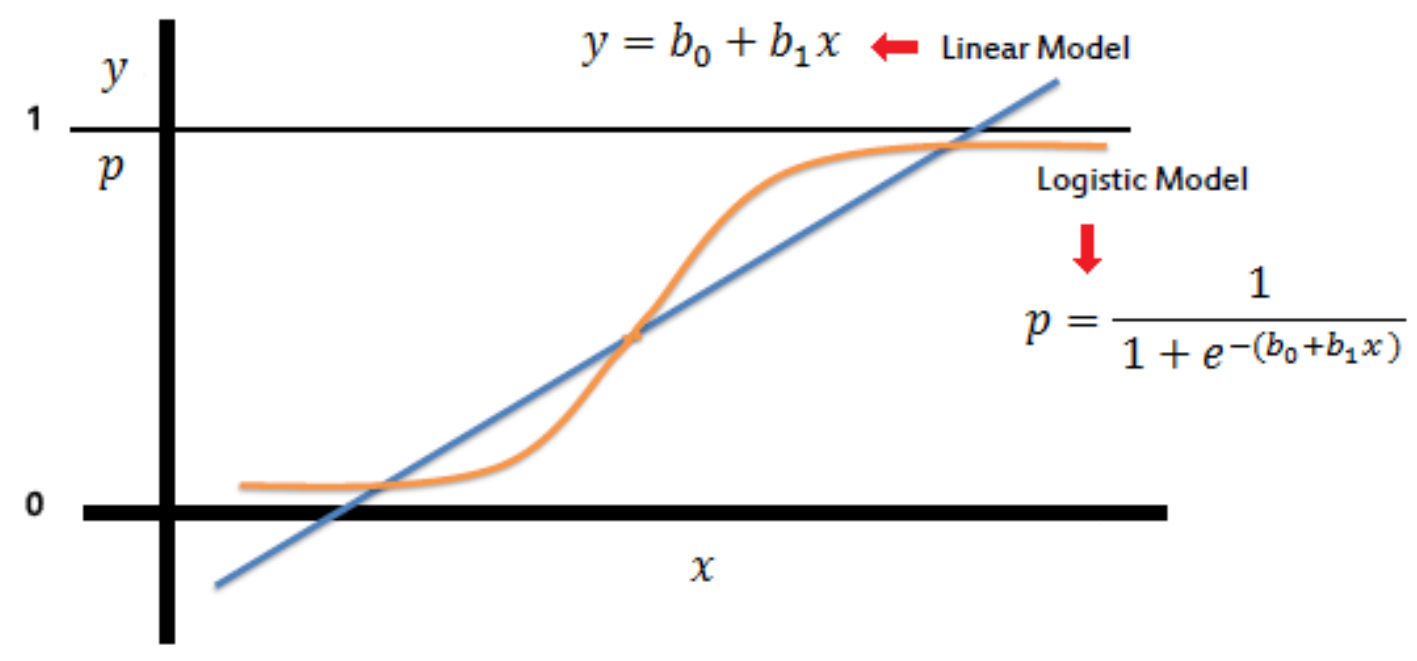

Figure 3: Linear regression vs Logistic regression (Sayad, 2012)

The assumption is that the predictor variables, $X i$, are related linearly to the odds of $\log \left(\frac{p}{1-p}\right)$ for the outcome of interest (Ottenbacher, Linn, Smith, Illig, Mancuso, \& Granger, 2004), and that there exists a hyperplane, or decision boundary, of all points $X_{i}$ that separates successful events from failed events (Dreiseitl \& Ohno-Machado, 2002).

Logistic regression may also be expressed as an odds function that an event $E$ occurs:

$$
\operatorname{Odds}(E)=\frac{p(E)}{p\left(E^{\prime}\right)}=\frac{p(E)}{1-p(E)}
$$


Here, the odds function can be transformed by taking the natural log of both sides to yield:

$$
\ln \frac{p(E)}{1-p(E)}=\ln p(E)-\ln (1-p(E))=e^{\beta_{o}+\beta_{1} X_{1}+\cdots+\beta_{i} X_{i}}
$$

Eq. 7

Now, the event $E$ is a dependent variable that takes on the values of 0 or 1 (Zaiontz, 2014). In this study, when the $\operatorname{Odds}(E)>0.5$; the bridge will be classified as structurally deficient; otherwise, the bridge is classified as not structurally deficient.

\section{$\underline{\text { Classification Trees }}$}

Classification trees (or regression trees) are rules that are developed for predicting the class of an object from the values of its predictor variables. They are a machine-learning classification method in which prediction models are obtained by recursively partitioning a learning sample of the data in which the predictor values and label classes are already known for each case. These partitions are signified by a node in the "tree" (Loh, 2011, Loh \& Shih, 1997). Figure 4 displays an example of a partitioned data set where the variables get assigned to the left node at each intermediate node when the specified condition is satisfied.
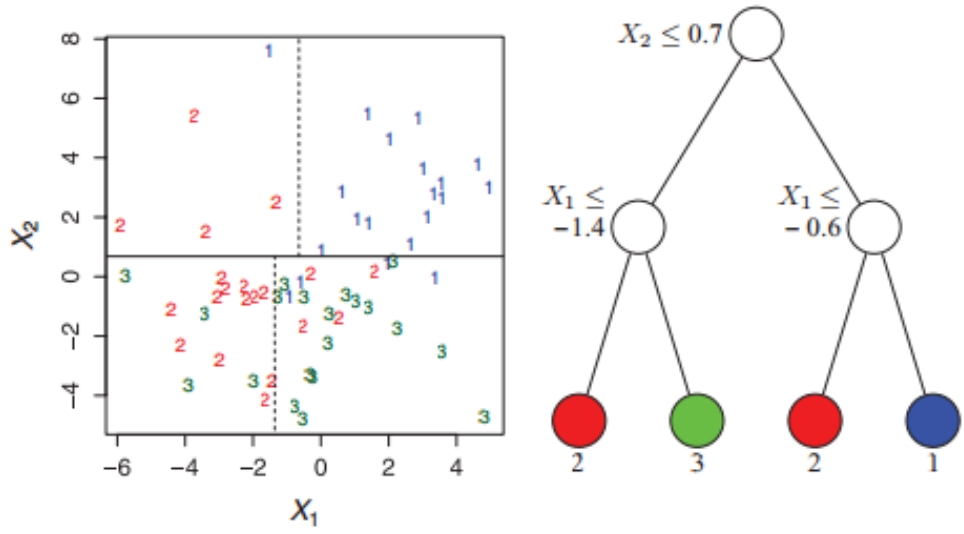

Figure 4: An example of a data set with three classes labeled 1, 2, and 3 (Loh, 2011) 
Gini index, a way of selecting attribute criterion, was chosen for this study as it is a way of measuring inequality (Loh, 2011, Langel \& Tillé, 2013). It is appropriate for our data divided into two classes as it generalizes a binomial variance. The empirical Gini index, defined in Equation 8, considers a variable $X_{j}$ in the special case of binary response $Y$. The relative class frequency, $N_{2 j} / N_{j}$, is the maximum likelihood estimator based on the number of observations indicated by the index $j$ (Strobl, Boulesteix, \& Augustin, 2007).

$$
G_{j}=2 \frac{N_{2 j}}{N_{j}}\left(1-\frac{N_{2 j}}{N_{j}}\right)
$$

Eq. 8

The data are then subjected to pre-pruning to keep results simple and easy to comprehend, and a minimum number of instances is set that each "leaf" must contain. The data are then post-pruned in two ways. First, the leaves are recursively merged with the same majority class. This reduces overfitting by generating the whole set of classification rules and then removing a number of rules and terms. This will prevent trees from becoming too large and difficult to grasp (Bramer, 2002). Secondly, the data is post-pruned using an m-estimate statistic. This estimate takes into account prior unconditional probabilities of classes and contains a tunable parameter $m$, which allows for adaptation based on noise level of the data (Dzeroski, Cestnik, \& Petrovski, 1993). The default m-estimate of 2 was used for this study.

\section{$\underline{\mathrm{CN} 2}$}

The CN2 rule learner and induction algorithm was developed in the 1980s based on previous classification processes; namely, the Iterative Dichotomiser 3 (ID3) and Algorithm quasioptimal (AQ) algorithms. The ID3 algorithm is applied to a set of data and generates a decision tree for classifying the data based on attribute selection by information gain (Umano, 
Okamoto, Hatono, Tamura, Kawachi, Umedzu, \& Kinoshita, 1994). The AQ algorithm is a rule induction technique that produces a complete and consistent description of classes (Michalski, Mozetic, Hong, \& Lavrač, 1986).

These older algorithms are far more basic and assume no noise in the data. The CN2 technique uses an if-then rule that was designed to modify and combine each of these algorithms to handle real-world domains by relaxing certain constraints that the induced description must classify the training data perfectly (Clark \& Niblett, 1989).

The nature of the ID3 algorithm allows for relative easy modification, while the AQ algorithm is more difficult to modify due to its dependence on specific training examples during search. The goals of the CN2 algorithm are to increase the space of rules searched, ensure accurate classification with simple rules, and utilize an efficient and simple to understand rule generation (Clark \& Niblett, 1989).

The CN2 algorithm utilizes three possible evaluation functions for implementation: the Laplace function, used in the original $\mathrm{CN} 2$ algorithm; the m-estimate of probability, used in more recent versions of the $\mathrm{CN} 2$ algorithm; and the weighted relative accuracy (WRACC) function, used in the CN2-SD algorithm.

The CN2-SD (subgroup discovery) is a modified version of CN2 that improves its evaluation measures and covering algorithm. The search methods and classification of instances were both adapted to reduce the number of induced rules and increase both rule coverage and rule significance. Therefore, due to its utilization with $\mathrm{CN} 2-\mathrm{SD}$, the WRACC function was chosen for this study:

$$
\text { WRACC }(\text { Class } \leftarrow \text { Cond })=p(\text { Cond }) *(p(\text { Class } \mid \text { Cond })-p(\text { Class }))
$$


where Class is the class value and Cond are feature attributes and their values (Lavrač, Kavsek, Flach, \& Todorovski, 2004).

Next, pre-pruning rules are defined. Likelihood ratio statistics (LRS) parameters are used at a $5 \%$ significance rating, while $10 \%$ weighted covering of the data was implemented.

\section{Orange Data Mining Software}

The six classification methods used in this study are implemented in a data mining and machine learning software called Orange. This comprehensive, component-based framework helps experienced researchers and beginners to perform data processing, modelling, and evaluation in many facets. Orange's capabilities include:

Data management and preprocessing, like sampling, filtering, scaling, discretization, and construction of new attributes

$>$ Induction of classification methods and regression models

$>$ Descriptive methods like association rules and clustering

$>$ Scoring of prediction models, including different hold-out schemes and range of scoring methods and visualization approaches.

Orange utilizes a visual programming paradigm and the graphical user's interface (GUI) is composed of multiple widgets that communicate through channels. Connected widgets, called a schema, can be written in a Python script or designed through a visual programming interface called Orange Canvas (Demšar, Zupan, Leban, \& Curk, 2004). For this study, the Canvas reads in the bridge element data sets as inputs, performed various machine learning classifications, and produced evaluations on the data. 


\section{RESULTS}

Six different classifications using six different methods were conducted for each of the elements; steel open girder - coated (element 107), prestressed concrete open girder (109), bare concrete deck with uncoated reinforcement (12), concrete deck with then overlay (18), concrete deck with rigid overlay (22), and bare concrete deck with coated reinforcement (26). For each of the bridge data sets, six classification methods were applied; naïve Bayes, $k$-nearest neighbor, support vector machines, logistic regression, classification trees, and the $\mathrm{CN} 2$ rule learner. The classification methods developed and produced results based on the attributes for each bridge. These attributes determined a prediction of "structurally deficient" or "not structurally deficient" for each bridge. Figure 5 displays the interface for each of the data sets.
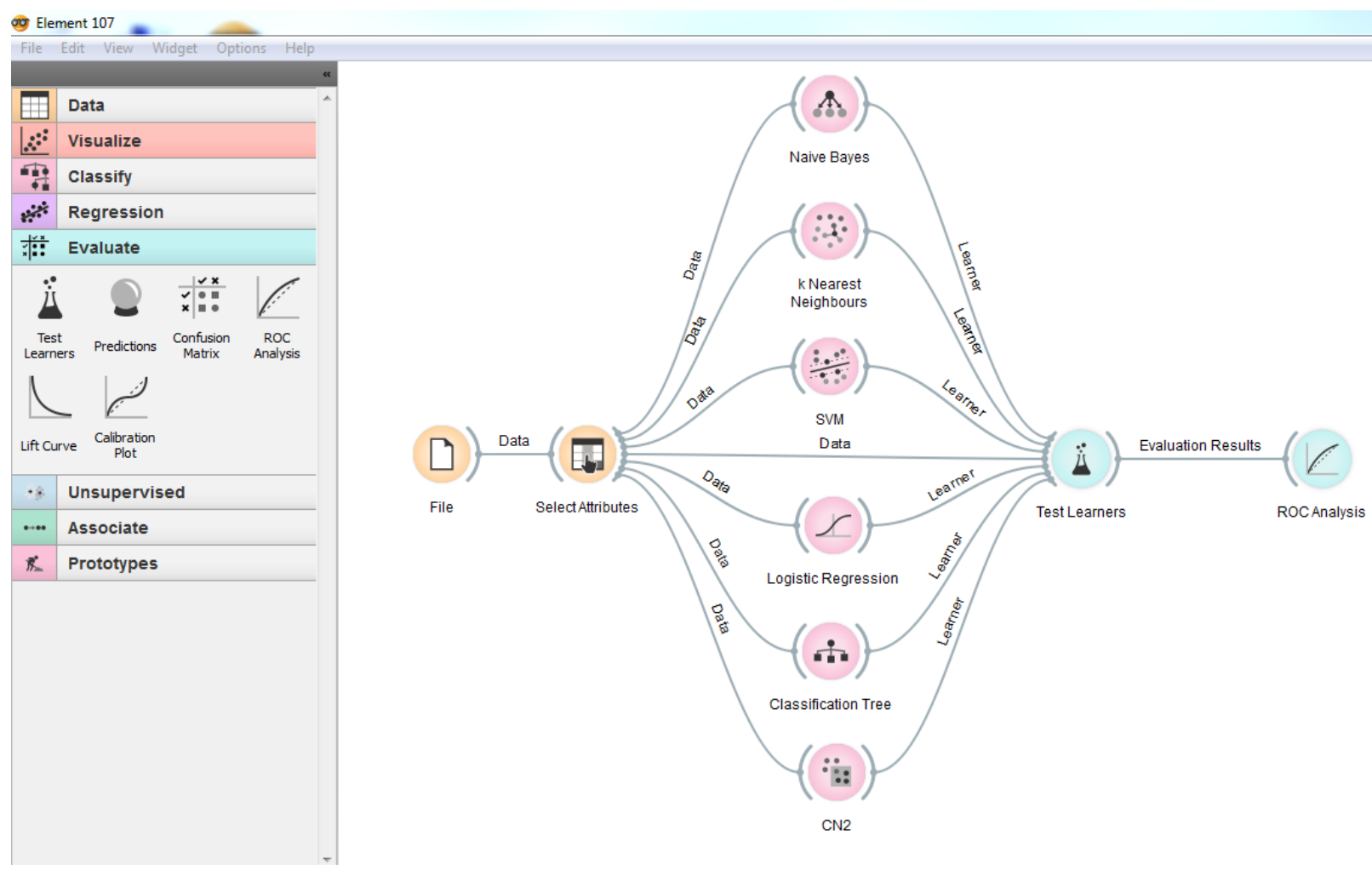

Figure 5: Orange Canvas for Bridge Element Data 
The Orange software contains many performance measures that report how well each classification method performed. These include:

Classification accuracy - the proportion of correctly classified examples

$>$ Sensitivity - (also called true positive rate, hit rate, and recall) the number of detected positive examples among all positive examples, e.g. the number of structurally deficient bridges correctly classified as structurally deficient

$>$ Specificity - the proportion of detected negative examples among all negative examples, e.g., the proportion of not structurally deficient bridges correctly recognized as not structurally deficient

Area under the ROC - the area under the receiver-operating characteristic curve

Information score - the average amount of information per classified instance

F-measure - a weighted harmonic mean of precision and recall, calculated as $2 *$ precision*recall/(precision+recall)

$>$ Precision - the number of positive examples among all examples classified as positive, e.g. the number of structurally deficient bridges among all diagnosed as structurally deficient

Recall - same as sensitivity, except that it is the proportion of relevant documents which are retrieved

Brier score - the measure of accuracy of probability assessments, which measures the average deviation between predicted probabilities of events and actual events Figure 6 displays all nine performance measures for steel open girders - coated (element 107). The receiver operating curve (ROC) illustrates the performance of a binary classifier system as its discrimination threshold is varied (Swets, 2014). Receiver operating curve points 
are produced by a maximum likelihood estimation and two parameters, the difference of means and the ratio of variances, are obtained. A number of indices can be calculated from these parameters; among which the area under the fitted smooth curve is the most popular (Hanely \& McNeil, 1982). The curve is plotted of the false positive rate (x-axis) against the true positive rate (y-axis), known as recall for machine learning purposes. The higher, and closer to 1 , the area under the ROC curve is, the better that classification method is at predicting structural deficiency of bridges. Area under the ROC curve was chosen as the most useful performance measure for this study. First, it is easily conveyed and understood, and, secondly, Orange has the ability to produce ROC plots for each classification method (Figures 7-12).

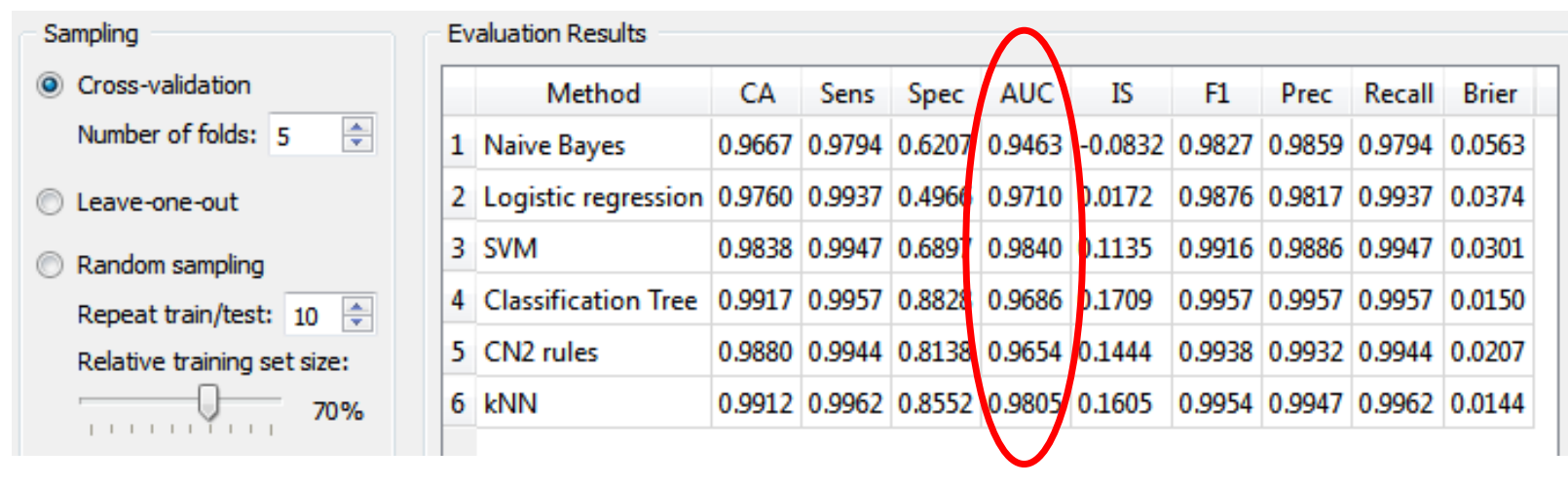

Figure 6: Performance Measures for Painted Steel Girders

As displayed in the figure above, the support vector machines classification method produces the highest area under the ROC curve for element 107. Subsequent analysis of each of the bridge elements was conducted, and the area under the ROC curve was the only performance measure used to evaluate performance.

Figures 7-12 display the ROC curves for each of the six elements studied. Within each of the figures, each of the six classification method curves is shown and results are compared. Table 7 following the curves summarizes the results of each element. 

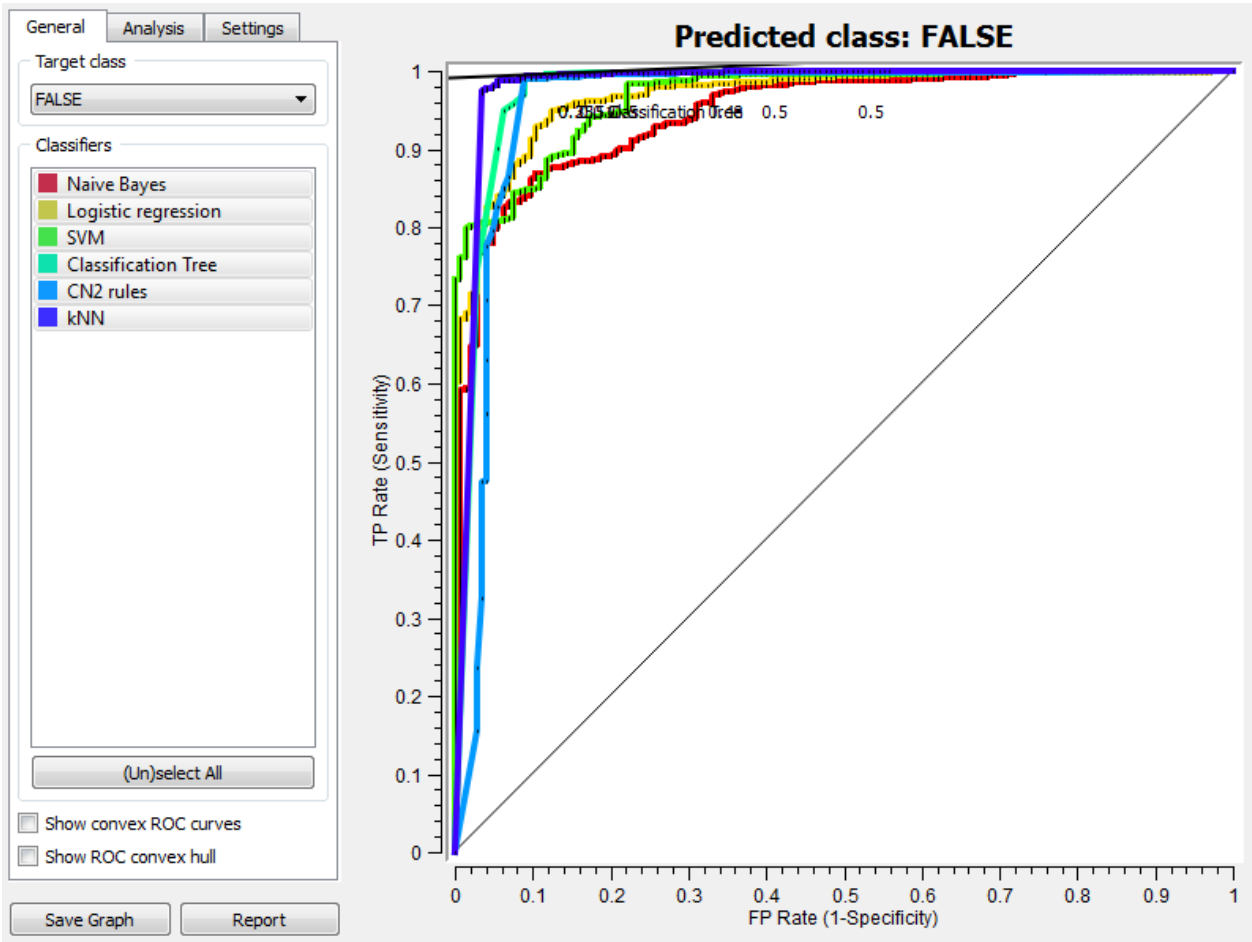

Figure 7: Receiver Operating Characteristic Curve for Painted Steel Girders
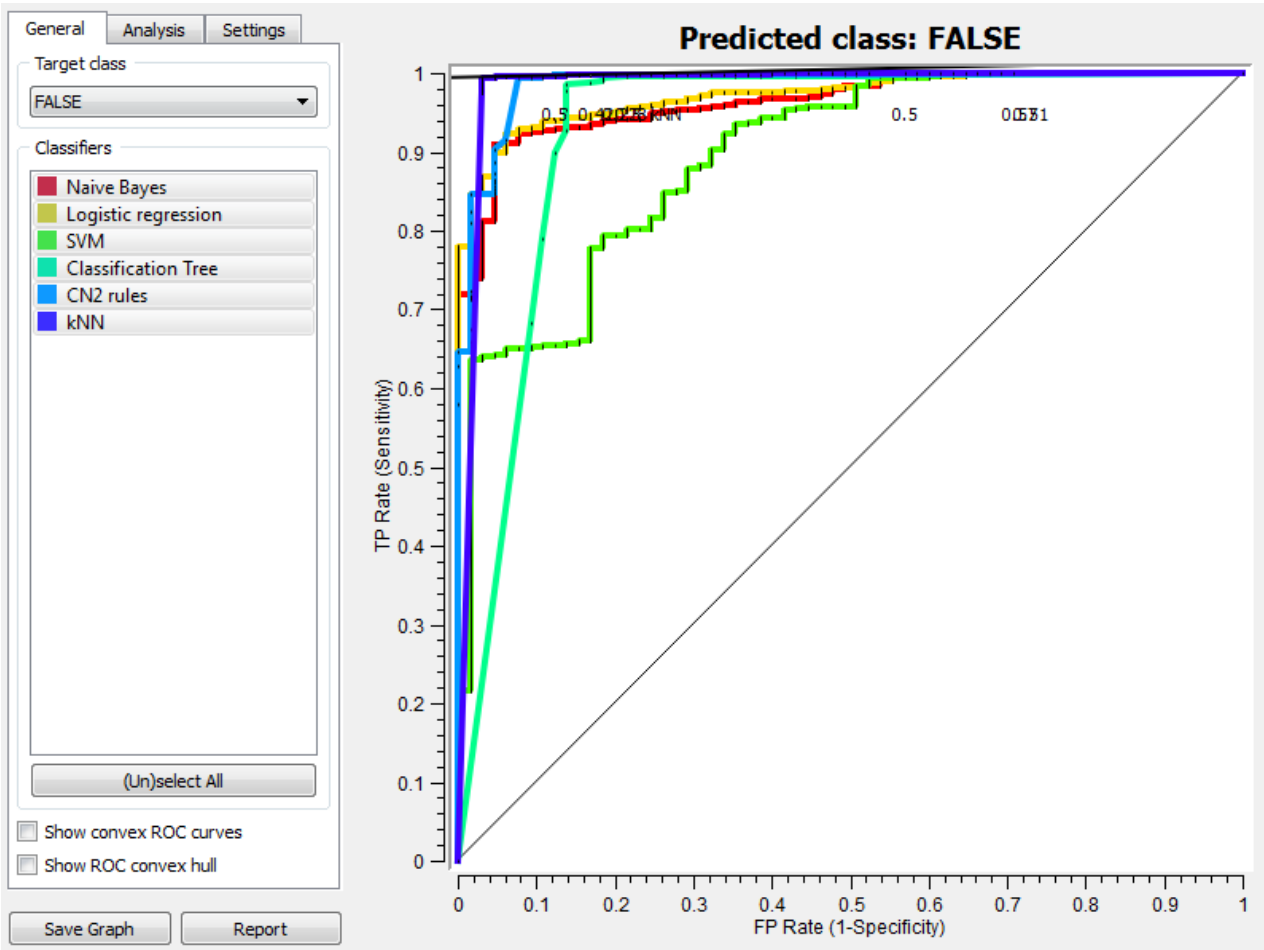

Figure 8: Receiver Operating Characteristic Curve for Prestressed Concrete Girders 

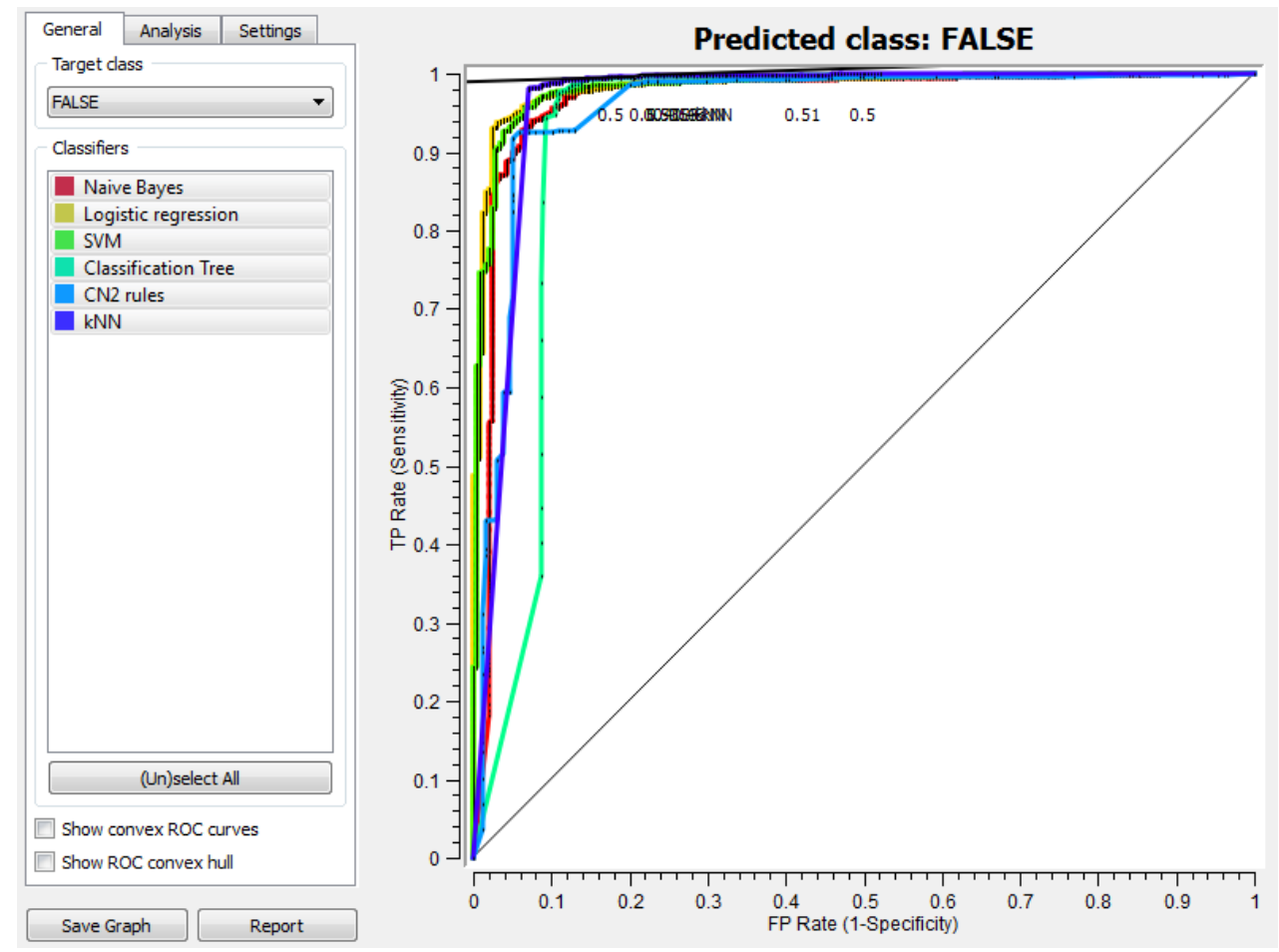

Figure 9: Receiver Operating Characteristic Curve for Bare Concrete Deck (Uncoated Rebar)
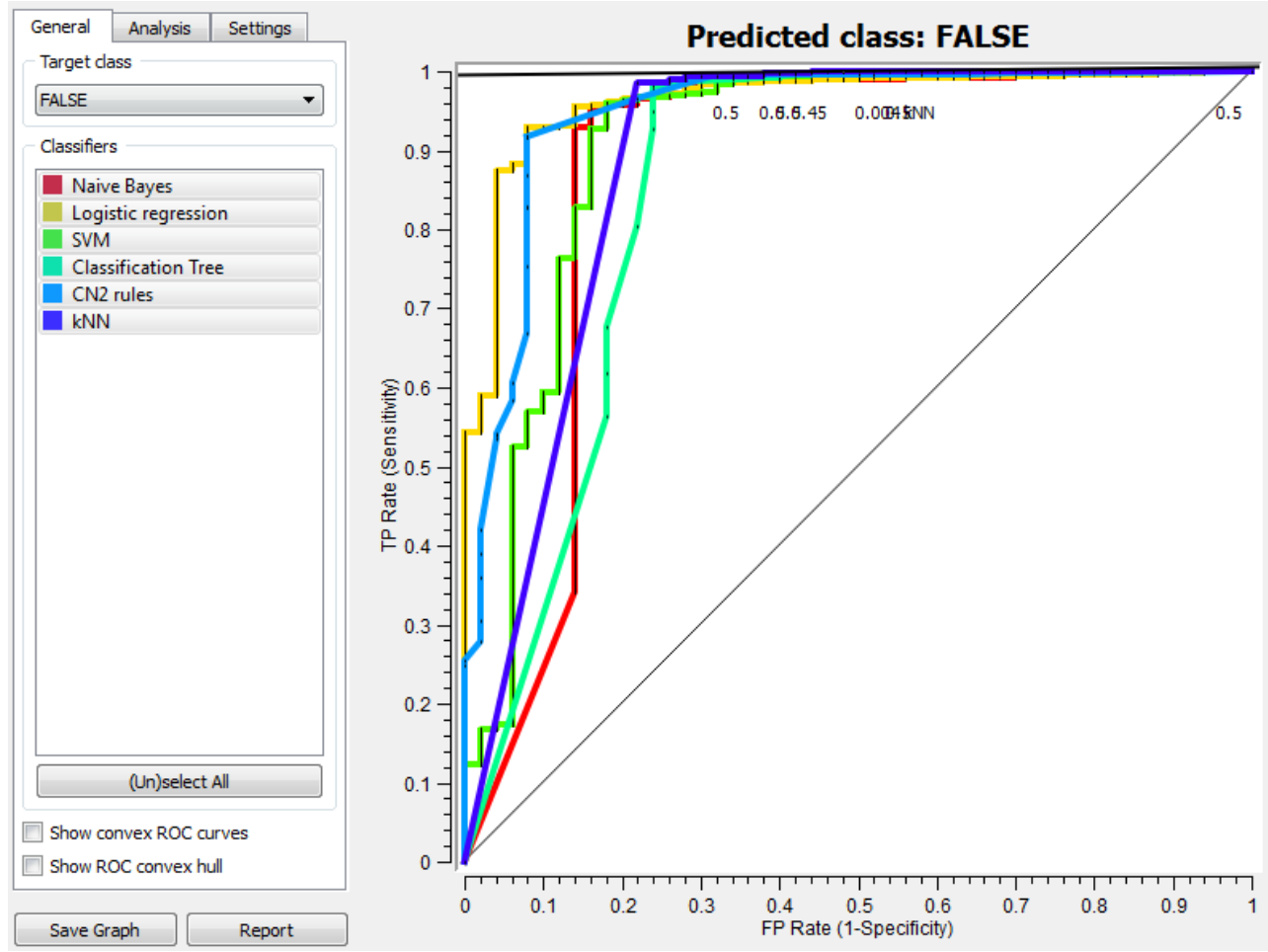

Figure 10: Receiver Operating Characteristic Curve for Concrete Deck (Thin Overlay) 

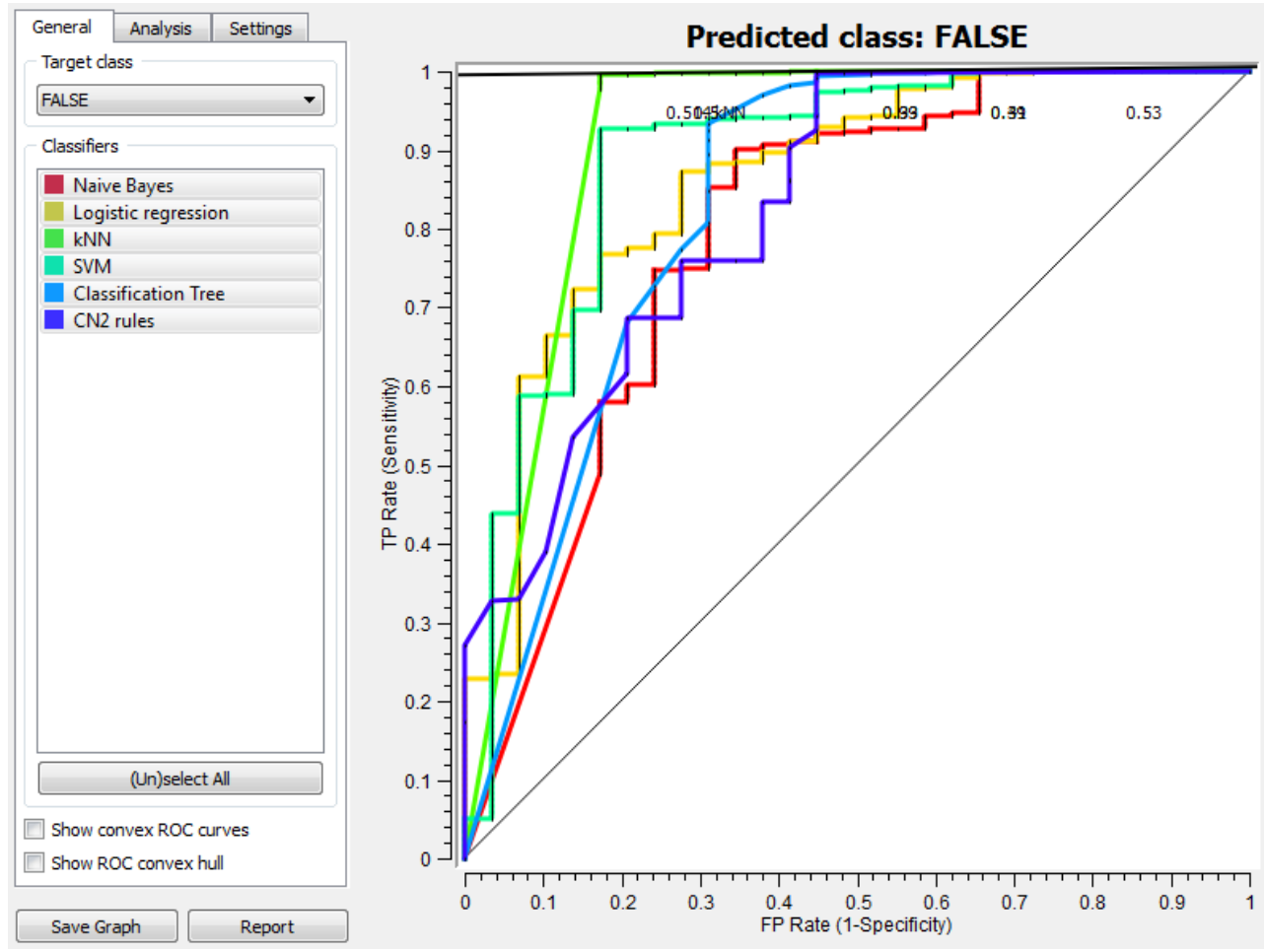

Figure 11: Receiver Operating Characteristic Curve for Concrete Deck (Rigid Overlay)
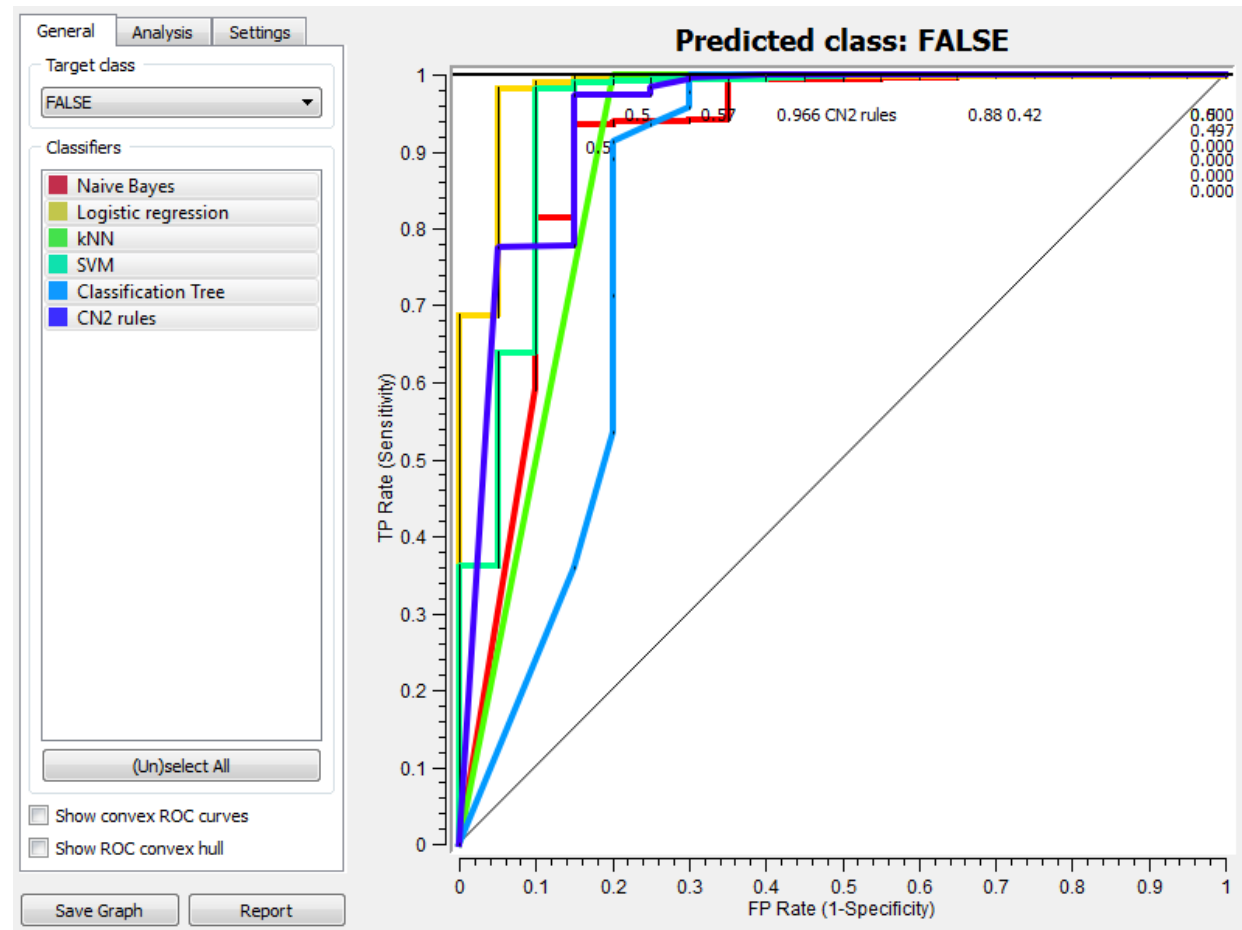

Figure 12: Receiver Operating Characteristic Curve for Bare Concrete Deck (Coated Rebar) 


\begin{tabular}{|c|c|c|c|c|c|c|c|}
\hline \multicolumn{8}{|c|}{ Area Under the Receiver Operating Characteristic Curve } \\
\hline \multirow[b]{2}{*}{ Classification Method } & \multicolumn{7}{|c|}{ Element } \\
\hline & 107 & 109 & 12 & 18 & 22 & 26 & Average \\
\hline Naïve Bayes & 0.9463 & 0.9654 & 0.9681 & 0.8750 & 0.8049 & 0.9077 & 0.91 \\
\hline k-Nearest Neighbor & 0.9805 & 0.9831 & 0.9622 & 0.8870 & 0.9140 & 0.8997 & 0.94 \\
\hline Support Vector Machines & 0.9840 & 0.9695 & 0.9847 & 0.9136 & 0.9117 & 0.9693 & 0.96 \\
\hline Logistic Regression & 0.9710 & 0.9730 & 0.9837 & 0.9628 & 0.8621 & 0.9807 & 0.96 \\
\hline Classification Trees & 0.9686 & 0.9259 & 0.9230 & 0.8583 & 0.8058 & 0.8612 & 0.89 \\
\hline CN2 Rule Learner & 0.9654 & 0.9859 & 0.9585 & 0.9508 & 0.8180 & 0.8743 & 0.93 \\
\hline
\end{tabular}

Table 7: Area Under the Receiver Operating Characteristic Curve Results Summary

Table 7 summarizes the results for each element and the area under the ROC curve for each classification method. The top performing classification methods, based on an overall average, were logistic regression, support vector machines, $k$-nearest neighbor, and the CN2 rule learner, respectively. Each of the methods was the top performing classifier in at least one of the elements, and the range between their averages was a slight three-hundredths. Classification trees and naïve Bayes produced consistently worse results and were not considered as an appropriate classifiers for structural deficiency.

\section{Significant Attributes}

Understanding which attributes of bridges influences structural deficiency the most is very important. The area under the ROC curve was investigated for the addition of each attribute. First, age was the only attribute selected and classification was conducted on each element data set. Then the additional elements were added one by one to determine the influence they had on accurate classification. The order in which the attributes for each element were selected was age $\rightarrow$ ADT $\rightarrow$ truck percentage $\rightarrow$ district $\rightarrow$ condition state profile $\rightarrow$ smart flags. Figure 13 displays the attribute influence on painted steel girders, Figure 14 displays the attribute 
influence on prestressed concrete girls, and Figure 15 displays the attribute influence on the deck elements.

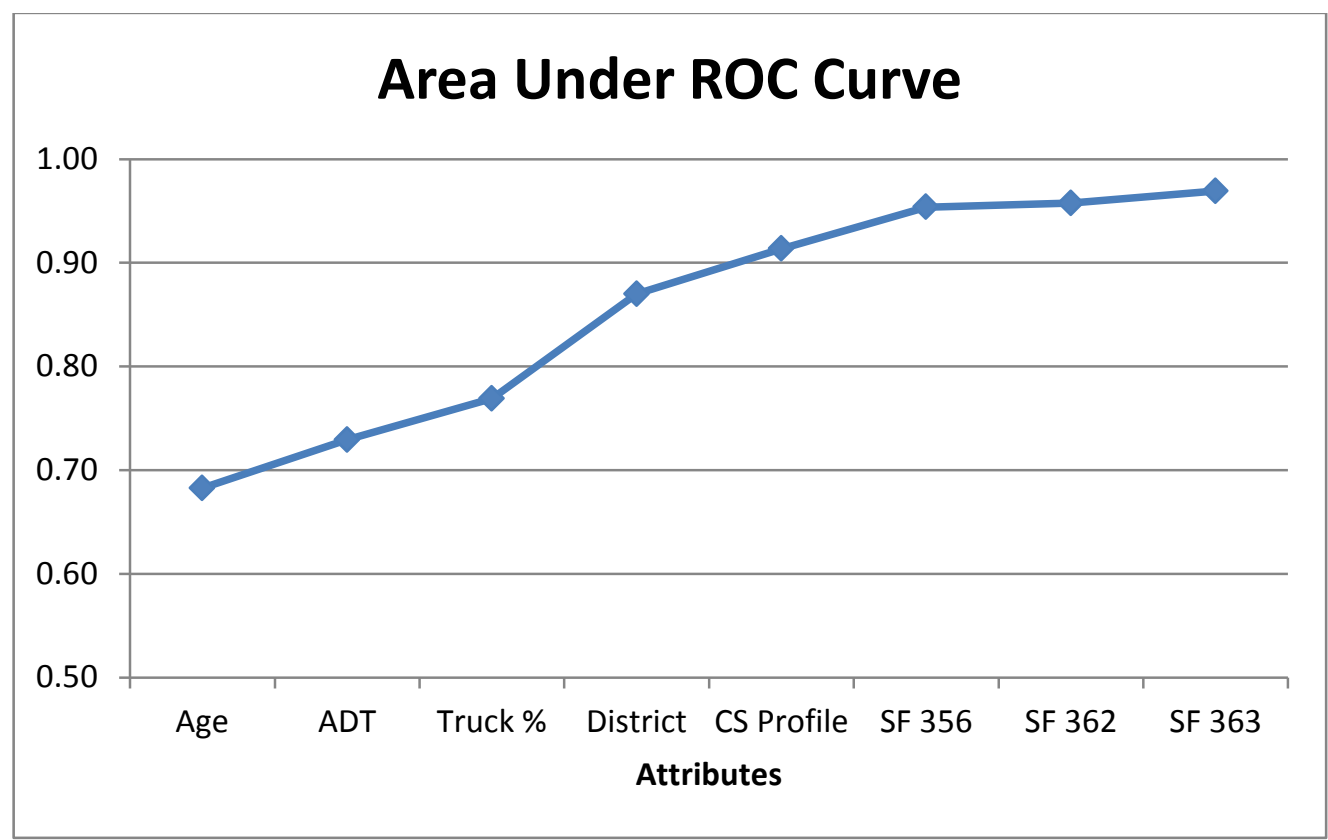

Figure 13: Attribute Influence on Painted Steel Girders

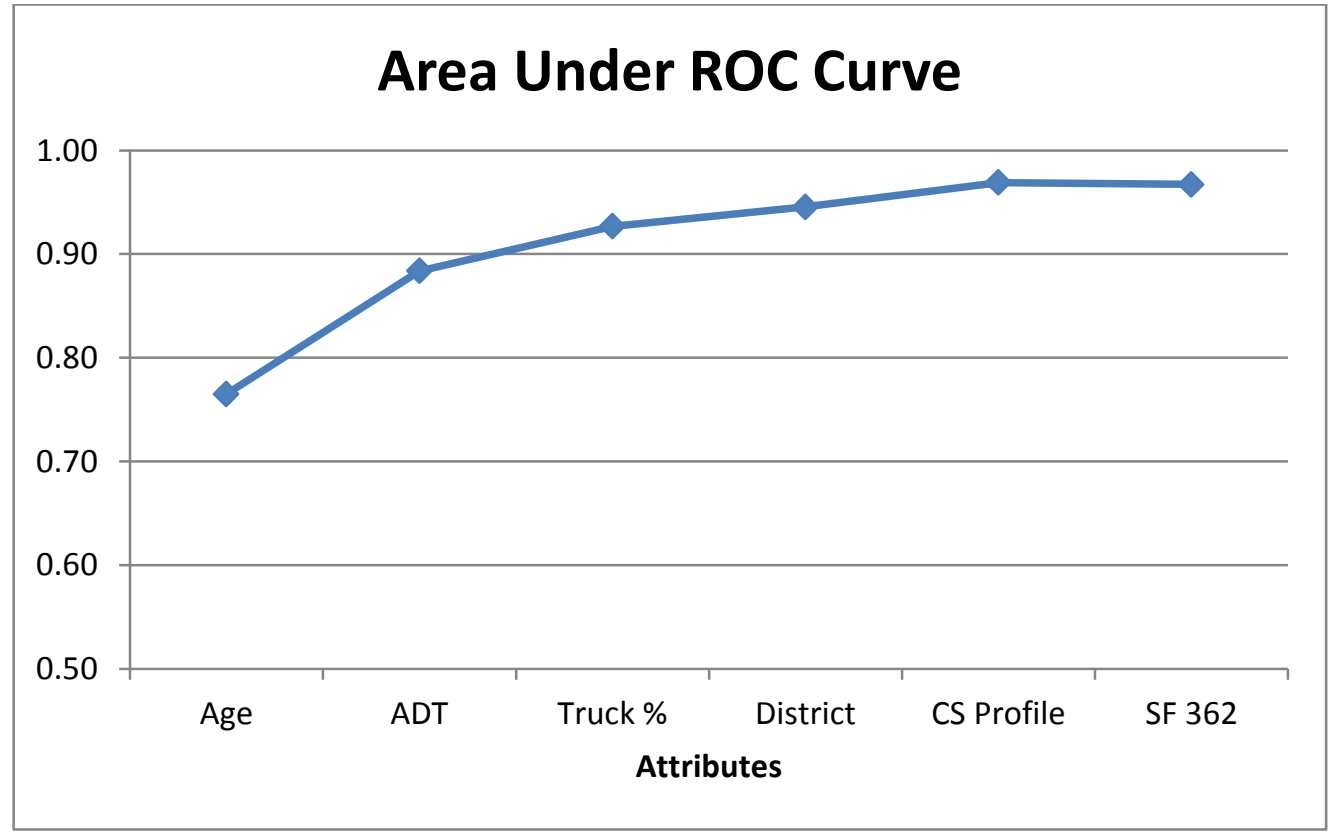

Figure 14: Attribute Influence on Prestressed Concrete Girders 


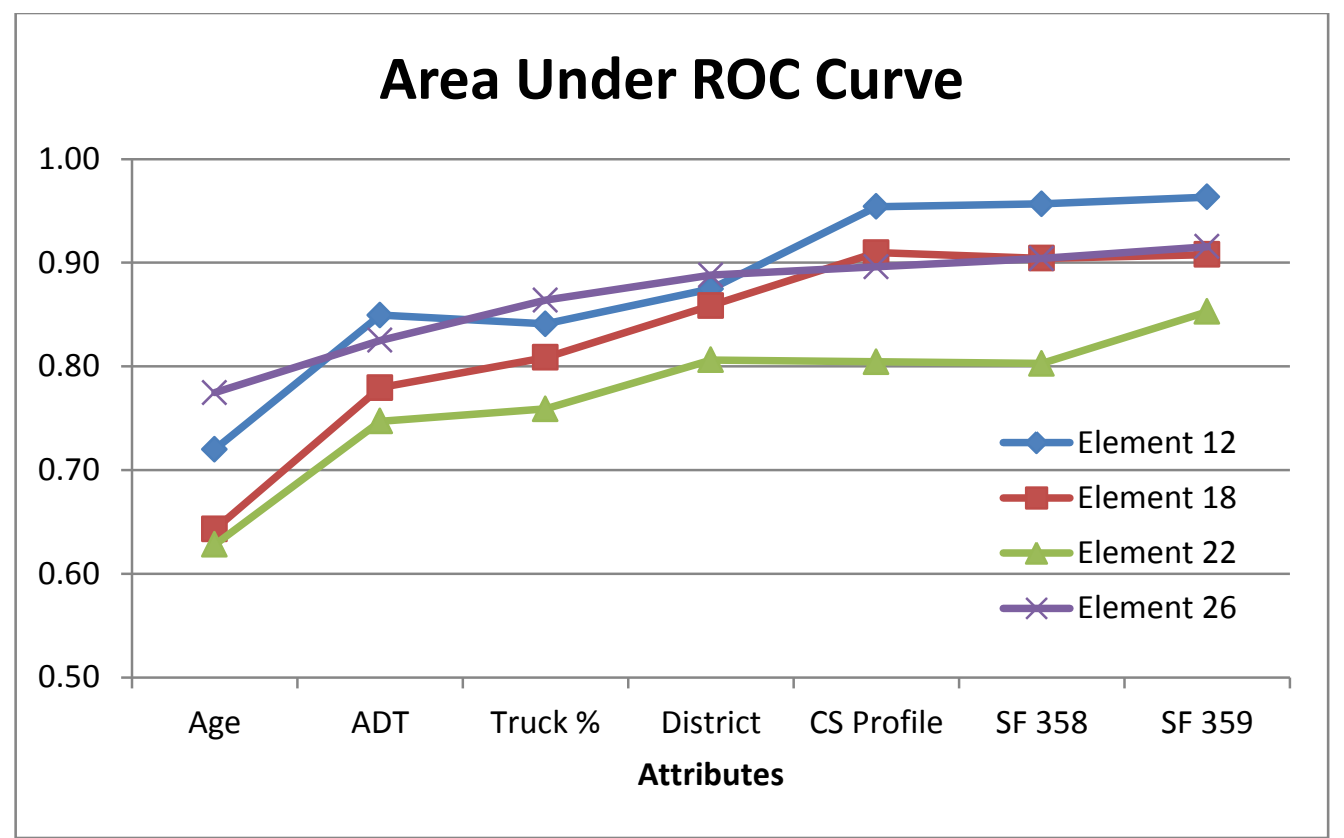

Figure 15: Attribute Influence on Deck Elements

Overall, the addition of individual attributes increases the classification performance in all elements with one exception: truck percentage in bare concrete decks with uncoated rebar (element 12). As expected, age and ADT were the two biggest influencers on classification performance. The condition state profiles seemed to have stronger influences on some elements than others.

\section{Selecting a Classification Method}

When determining which classification method was best to recommend as the most useful classifier of structural deficiency, two criteria were taken into account. First, the classifier must consistently produce strong classifying results, and second, these results must be easily understood by the user.

Classification trees and naïve Bayes were first eliminated as possible recommendations due to their poor results. Next, $k$-nearest neighbor and support vector machines were eliminated due to their more complex classifiers and black-box nature. For instance, support vector 
machines used a radial basis kernel function to transform, in this case, 6-8 dimensions (depending on the element). This produced 6-8 dimensional hyperplane equations that are completely abstract and of no significance to the user. Finally, the decision between logistic regression and $\mathrm{CN} 2$ rule learner came down to simplicity and ability to understand for the user.

The logistic regression classifier creates best-fit $\beta$ coefficients to produce a classifier. Although still abstract to the user, Orange has the capability to produce nomographs of logistic regression classifier results. A nomograph consists of three (or more) parallel graduated lines of known values on any two (or more) scales that determines a straight index line that passes through the solution value of the third (or fourth, fifth, etc.) (Encyclopedia Britannica, 2014). Painted steel girders (107) contained 8 attributes, making it harder to understand the significance of the straight index line and the prediction it produces. Figure 16 displays the results of element 107's nomograph, and the nomographs for each other element are displayed in Appendix B.

Ultimately, it was determined that the $\mathrm{CN} 2$ rule learner would be the most useful for users by providing them with easy to understand "if...then" rules and results. Using the adapted version, the CN2-SD, improves the original algorithm's evaluation measures and covering. Additionally, the number of induced rules was reduced and both rule coverage and rule significance were increased. Orange has the capability of printing the rules produced by the algorithm for each of the elements studied. Figures 17-22 display these rules in a clean and clear manner for the user. 


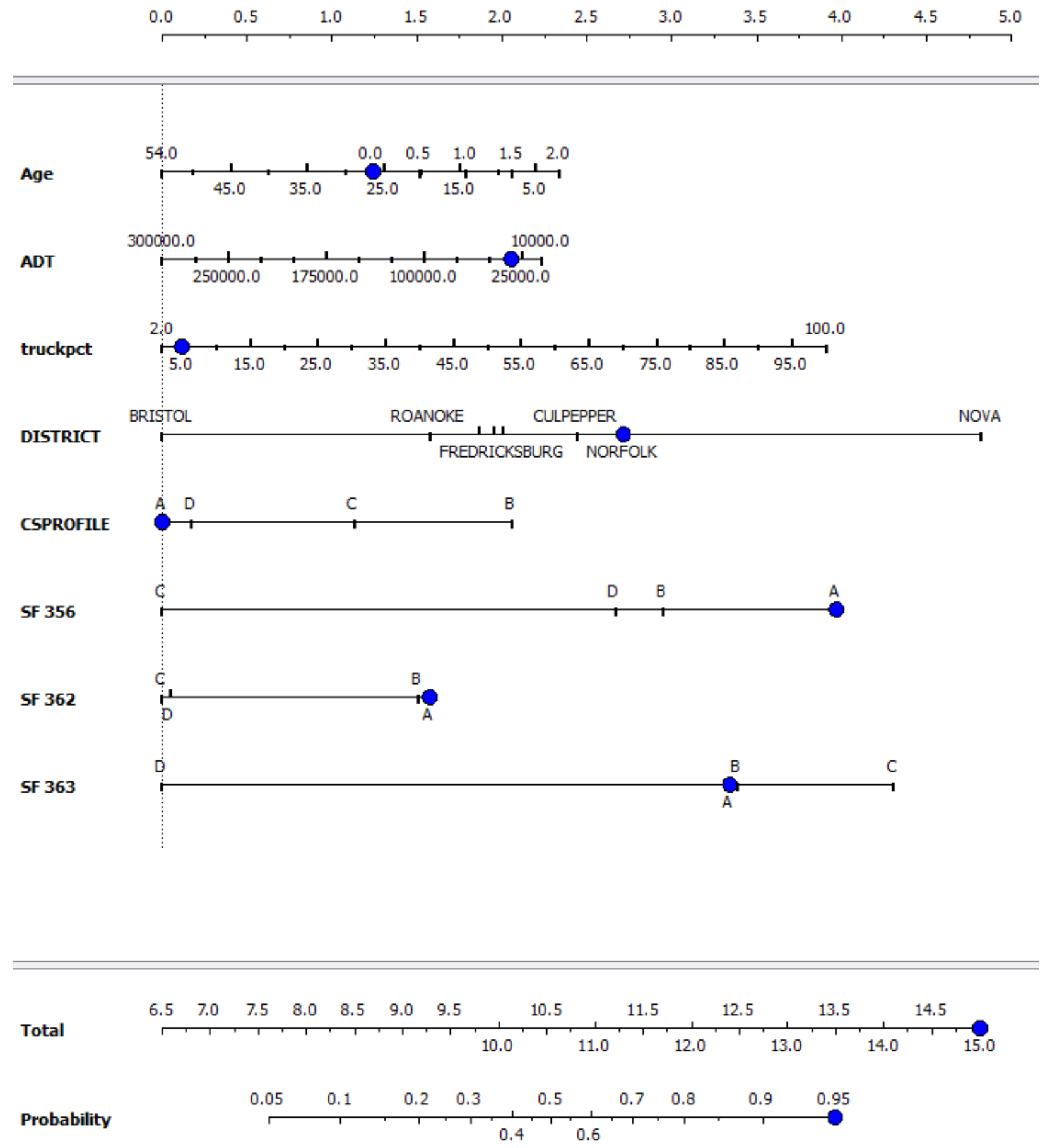

Figure 16: Nomograph of Painted Steel Girders 


\begin{tabular}{|c|c|c|c|c|}
\hline $\begin{array}{l}\text { Rule } \\
\text { length }\end{array}$ & $\begin{array}{l}\text { Rule } \\
\text { quality }\end{array}$ & Coverage & $\begin{array}{l}\text { Predicted } \\
\text { class }\end{array}$ & Rule \\
\hline 2 & 0.026 & 3061.000 & FALSE & IF SF $356=$ A AND SF $363=$ A THEN SD=FALSE \\
\hline 4 & 0.063 & 537.000 & FALSE & $\begin{array}{l}\text { IF Age }<=42.00 \text { AND Age }>14.00 \text { AND ADT }>13344.00 \text { AND SF } 362=\text { A THEN } \\
\text { SD }=\text { FALSE }\end{array}$ \\
\hline 4 & 0.355 & 65.000 & TRUE & $\begin{array}{l}\text { IF } S F 356=C \text { AND CSPROFILE }=A \text { AND ADT }>16785.00 \text { AND ADT }<=29899.00 \text { THEN } \\
\text { SD }=\text { TRUE }\end{array}$ \\
\hline 3 & 0.226 & 42.000 & TRUE & IF CSPROFILE=D AND SF $363=\mathrm{D}$ AND SF $356=\mathrm{A}$ THEN SD=TRUE \\
\hline 4 & 0.242 & 14.000 & TRUE & IF SF $356=$ C AND SF $363=$ A AND Age $>30.00$ AND Age $<=36.00$ THEN SD $=$ TRUE \\
\hline 5 & 0.253 & 11.000 & TRUE & $\begin{array}{l}\text { IF CSPROFILE=D AND DISTRICT=BRISTOL AND truckpct }<=11.00 \text { AND } \\
\text { Age }<=30.00 \text { AND ADT }<=13344.00 \text { THEN SD=TRUE }\end{array}$ \\
\hline $\mathbf{s}$ & 0.198 & 10.000 & TRUE & $\begin{array}{l}\text { IF SF } 362=\text { C AND SF } 363=C \text { AND ADT }>23000.00 \text { AND ADT }<=52038.00 \text { AND } \\
\text { Age }>40.00 \text { THEN SD }=\text { TRUE }\end{array}$ \\
\hline 3 & 0.207 & 5.000 & TRUE & IF SF $362=C$ AND ADT $>80407.00$ AND ADT $<=85749.00$ THEN SD $=$ TRUE \\
\hline 3 & 0.210 & 4.000 & TRUE & IF SF $356=\mathrm{B}$ AND Age $>42.00$ AND SF $363=$ A THEN SD $=$ TRUE \\
\hline 2 & 0.199 & 3.000 & TRUE & IF SF $362=D$ AND Age $<=13.00$ THEN $S D=$ TRUE \\
\hline 4 & 0.249 & 3.000 & TRUE & $\begin{array}{l}\text { IF CSPROFILE }=\text { D AND ADT }<=4250.00 \text { AND Age }<=24.00 \text { AND ADT }>3953.00 \text { THEN } \\
S D=\text { TRUE }\end{array}$ \\
\hline 2 & 0.111 & 1.000 & TRUE & IF SF $362=D$ AND Age $>42.00$ THEN SD $=$ TRUE \\
\hline 3 & 0.166 & 3.000 & TRUE & IF SF $362=\mathrm{C}$ AND CSPROFILE $=$ A AND Age $<=44.00$ THEN SD $=$ TRUE \\
\hline 2 & 0.166 & 1.000 & TRUE & IF SF $356=\mathrm{C}$ AND SF $362=\mathrm{B}$ THEN SD $=$ TRUE \\
\hline 3 & 0.200 & 1.000 & TRUE & IF DISTRICT $=$ RICHMOND AND SF $363=\mathrm{C}$ AND Age>44.00 THEN SD $=$ TRUE \\
\hline 4 & 0.071 & 14.000 & TRUE & $\begin{array}{l}\text { IF SF } 363=C \text { AND DISTRICT }=\text { RICHMOND AND ADT }>48110.00 \text { AND Age }>30.00 \\
\text { THEN } S D=T R U E\end{array}$ \\
\hline 3 & 0.500 & 1.000 & TRUE & IF ADT $<=3000.00$ AND Age $>37.00$ AND ADT $>1500.00$ THEN SD $=$ TRUE \\
\hline 3 & 0.200 & 5.000 & TRUE & IF SF $356=C$ AND DISTRICT $=$ RICHMOND AND Age $<=28.00$ THEN SD $=$ TRUE \\
\hline
\end{tabular}

Figure 17: CN2 Rules for Painted Steel Girders

\begin{tabular}{|c|c|c|c|c|}
\hline $\begin{array}{l}\text { Rule } \\
\text { length }\end{array}$ & $\begin{array}{l}\text { Rule } \\
\text { quality }\end{array}$ & Coverage & $\begin{array}{l}\text { Predicted } \\
\text { class }\end{array}$ & Rule \\
\hline 2 & 0.014 & 2184.000 & FALSE & IF ADT $<=37769.00$ AND AGE $<=37.00$ THEN SD $=$ FALSE \\
\hline 2 & 0.028 & 404.000 & FALSE & IF SF $362=$ A AND ADT $<=12068.00$ THEN SD $=$ FALSE \\
\hline 2 & 0.302 & 22.000 & TRUE & IF CSPROFILE=D AND SF $362=\mathrm{D}$ THEN SD=TRUE \\
\hline 6 & 0.247 & 11.000 & TRUE & $\begin{array}{l}\text { IF CSPROFILE=D AND AGE }>33.00 \text { AND pct truck }<=2.00 \text { AND pct truck }>1.00 \text { AND } \\
\text { AGE }<=38.00 \text { AND ADT }>23585.00 \text { THEN } \text { SD }=\text { TRUE }\end{array}$ \\
\hline 4 & 0.450 & 15.000 & TRUE & $\begin{array}{l}\text { IF AGE }>37.00 \text { AND ADT }>12068.00 \text { AND ADT }<=13112.00 \text { AND ADT }>13000.00 \\
\text { THEN SD }=\text { TRUE }\end{array}$ \\
\hline 4 & 0.344 & 23.000 & TRUE & $\begin{array}{l}\text { IF AGE }>40.00 \text { AND CSPROFILE }=D \text { AND ADT }>509.00 \text { AND ADT }<=12500.00 \text { THEN } \\
S D=T R U E\end{array}$ \\
\hline 3 & 0.832 & 5.000 & TRUE & IF ADT $>37769.00$ AND ADT $<=38112.00$ AND AGE $>33.00$ THEN SD $=$ TRUE \\
\hline 3 & 1.000 & 1.000 & TRUE & IF ADT $>43074.00$ AND ADT $<=43842.00$ AND AGE $>31.00$ THEN SD $=$ TRUE \\
\hline
\end{tabular}

Figure 18: CN2 Rules for Prestressed Concrete Girders 


\begin{tabular}{|c|c|c|c|c|}
\hline $\begin{array}{c}\text { Rule } \\
\text { length }\end{array}$ & $\begin{array}{c}\text { Rule } \\
\text { quality }\end{array}$ & Coverage & $\begin{array}{l}\text { Predicted } \\
\text { class }\end{array}$ & Rule \\
\hline 3 & 0.015 & 6398.000 & FALSE & IF Age $<=44.00$ AND Age $<=39.00$ AND ADT $<=37209.00$ THEN SD $=$ FALSE \\
\hline 1 & 0.034 & 1326.000 & FALSE & IF DK_CS $=B$ THEN SD=FALSE \\
\hline 1 & 0.078 & 1006.000 & FALSE & IF DK_CS=A THEN SD=FALSE \\
\hline 2 & 0.321 & 161.000 & TRUE & IF DK_CS $=E$ AND ADT $>887.00$ THEN SD $=$ TRUE \\
\hline 3 & 0.329 & 141.000 & TRUE & IF DK_CS=D AND ADT $>2748.00$ AND Age $>33.00$ THEN SD=TRUE \\
\hline 7 & 0.156 & 36.000 & TRUE & $\begin{array}{l}\text { IF DK_CS }=\text { D AND Age }>44.00 \text { AND PetTK }<=2.00 \text { AND ADT }>136.00 \text { AND } \\
\text { ADT }>310.00 \text { AND ADT }<=2261.00 \text { AND Age }<=60.00 \text { THEN SD }=\text { TRUE }\end{array}$ \\
\hline 3 & 0.181 & 9.000 & TRUE & IF DK_CS=D AND ADT< $<=136.00$ AND Age $>41.00$ THEN SD=TRUE \\
\hline 4 & 0.165 & 7.000 & TRUE & IF DK_CS $=$ C AND SF $358=D$ AND Age $>40.00$ AND Age $<=47.00$ THEN SD $=$ TRUE \\
\hline 4 & 0.120 & 3.000 & TRUE & IF SF $358=C$ AND SF $359=C$ AND DK_CS=D AND Age $>55.00$ THEN SD=TRUE \\
\hline 6 & 0.136 & 3.000 & TRUE & $\begin{array}{l}\text { IF } S F 358=C \text { AND DK_CS }=C \text { AND Age }>43.00 \text { AND ADT }>10881.00 \text { AND } \\
\text { ADT }<=16110.00 \text { AND PCtTK }<=4.00 \text { THEN SD }=\text { TRUE }\end{array}$ \\
\hline 5 & 0.105 & 2.000 & TRUE & $\begin{array}{l}\text { IF DK_CS }=\text { C AND Age }>37.00 \text { AND Age }>66.00 \text { AND Age }<=68.00 \text { AND ADT }<=149.00 \\
\text { THEN SD }=\text { TRUE }\end{array}$ \\
\hline 3 & 0.117 & 2.000 & TRUE & IF SF $359=\mathrm{D}$ AND Age $<=28.00$ AND SF $358=\mathrm{N}$ THEN SD=TRUE \\
\hline $\mathbf{s}$ & 0.133 & 2.000 & TRUE & $\begin{array}{l}\text { IF DK_CS }=\text { E AND PctTK }<=0.00 \text { AND Age }>56.00 \text { AND ADT }>147.00 \text { AND } \\
\text { ADT }<=577.00 \text { THEN SD }=\text { TRUE }\end{array}$ \\
\hline 6 & 0.173 & 4.000 & TRUE & $\begin{array}{l}\text { IF SF } 359=\text { C AND ADT }>2233.00 \text { AND SF } 358=C \text { AND PctTK }<=2.00 \text { AND Age }>45.00 \\
\text { AND ADT }<=4258.00 \text { THEN SD }=\text { TRUE }\end{array}$ \\
\hline 4 & 0.200 & 2.000 & TRUE & $\begin{array}{l}\text { IF DK_CS }=D \text { AND ADT }>11078.00 \text { AND ADT }<=12632.00 \text { AND Age }<=32.00 \text { THEN } \\
\text { SD }=T \text { TRUE }\end{array}$ \\
\hline 2 & 0.125 & 1.000 & TRUE & IF SF $359=E$ AND Age $>52.00$ THEN SD=TRUE \\
\hline 3 & 0.143 & 1.000 & TRUE & IF District=Richmond AND SF $359=\mathrm{D}$ AND Age $>49.00$ THEN SD=TRUE \\
\hline 6 & 0.222 & 3.000 & TRUE & $\begin{array}{l}\text { IF DK_CS }=\text { C AND SF } 359=\text { B AND District }=\text { Richmond AND PctTK }>4.00 \text { AND } \\
\text { Age }<=40.00 \text { AND Age }>36.00 \text { THEN SD }=\text { TRUE }\end{array}$ \\
\hline 4 & 0.250 & 1.000 & TRUE & $\begin{array}{l}\text { IF Age }>39.00 \text { AND ADT }>1904.00 \text { AND ADT }<=1906.00 \text { AND Age }<=47.00 \text { THEN } \\
\text { SD }=\text { TRUE }\end{array}$ \\
\hline 5 & 0.333 & 1.000 & TRUE & $\begin{array}{l}\text { IF SF } 358=C \text { AND PetTK }>5.00 \text { AND District=Richmond AND PctTK }<=7.00 \text { AND SF } \\
359=B \text { THEN } S D=T R U E\end{array}$ \\
\hline 3 & 0.014 & 36.000 & TRUE & IF DK_CS=C AND District=Bristol AND ADT $>1912.00$ THEN SD $=$ TRUE \\
\hline
\end{tabular}

Figure 19: CN2 Rules for Bare Concrete Deck (Uncoated Rebar)

\begin{tabular}{|c|c|c|c|c|}
\hline $\begin{array}{l}\text { Rule } \\
\text { length }\end{array}$ & $\begin{array}{l}\text { Rule } \\
\text { quality }\end{array}$ & Coverage & $\begin{array}{l}\text { Predicted } \\
\text { class }\end{array}$ & Rule \\
\hline 3 & 0.006 & 2472.000 & FALSE & IF SF $358=N$ AND Age $<=41.00$ AND adt $\angle=43842.00$ THEN SD $=$ FALSE \\
\hline 2 & 0.011 & 954.000 & FALSE & IF DK_CS $=$ A AND Age $<=62.00$ THEN SD $=$ FALSE \\
\hline 2 & 0.037 & 686.000 & FALSE & IF DK_CS $=B$ AND Age $<=70.00$ THEN SD $=F A L S E$ \\
\hline $\mathbf{s}$ & 0.259 & 22.000 & TRUE & $\begin{array}{l}\text { IF DK_CS }=\text { C AND adt }<=6641.00 \text { AND adt }>3658.00 \text { AND Pct } T K<=3.00 \text { AND } \\
\text { adt }>4125.00 \text { THEN SD }=\text { TRUE }\end{array}$ \\
\hline 5 & 0.242 & 15.000 & TRUE & $\begin{array}{l}\text { IF District=NOVA AND SF } 359=\text { D AND SF } 358=N \text { AND adt }<=44541.00 \text { AND } \\
\text { Pet } T K<=1.00 \text { THEN SD }=\text { TRUE }\end{array}$ \\
\hline 3 & 0.362 & 8.000 & TRUE & IF Age >62.00 AND District=Norfolk AND SF 359=C THEN SD=TRUE \\
\hline 3 & 0.214 & 3.000 & TRUE & IF DK_CS $=C$ AND Age $>68.00$ AND adt $<=1723.00$ THEN SD $=$ TRUE \\
\hline 5 & 0.181 & 2.000 & TRUE & $\begin{array}{l}\text { IF SF } 359=\text { C AND Age }>48.00 \text { AND adt }>3782.00 \text { AND Pct } T K<=2.00 \text { AND Pct } \\
\text { TK }>0.00 \text { THEN SD }=\text { TRUE }\end{array}$ \\
\hline 2 & 0.152 & 26.000 & TRUE & IF DK_CS $=$ D AND adt $>3682.00$ THEN SD $=$ TRUE \\
\hline 2 & 0.025 & 13.000 & TRUE & IF District=Richmond AND DK_CS=A THEN SD=TRUE \\
\hline 4 & 0.166 & 3.000 & TRUE & $\begin{array}{l}\text { IF Age }<=22.00 \text { AND District=Staunton AND Age }>21.00 \text { AND adt }>800.00 \\
\text { THEN SD }=\text { TRUE }\end{array}$ \\
\hline 3 & 1.000 & 1.000 & TRUE & IF $a d t<=367.00$ AND adt $>364.00$ AND Age $<=40.00$ THEN SD $=$ TRUE \\
\hline
\end{tabular}

Figure 20: CN2 Rules for Concrete Deck (Thin Overlay) 


\begin{tabular}{|c|c|c|c|c|}
\hline $\begin{array}{l}\text { Rule } \\
\text { length }\end{array}$ & $\begin{array}{l}\text { Rule } \\
\text { quality }\end{array}$ & Coverage & $\begin{array}{l}\text { Predicted } \\
\text { class }\end{array}$ & Rule \\
\hline 3 & 0.006 & 1164.000 & FALSE & IF $a d t<=27800.00$ AND adt $>4356.00$ AND Age $>19.00$ THEN SD $=$ FALSE \\
\hline 1 & 0.011 & 754.000 & FALSE & IF adt $<=3542.00$ THEN SD $=$ FALSE \\
\hline 2 & 0.034 & 342.000 & FALSE & If Age $<=57.00$ AND adt $>28116.00$ THEN SD=FALSE \\
\hline 2 & 0.375 & 11.000 & TRUE & If Age $>57.00$ AND adt $>11759.00$ THEN SD=TRUE \\
\hline 3 & 0.221 & 4.000 & TRUE & IF $a d t<=4356.00$ AND adt $>3955.00$ AND Age $>58.00$ THEN SD $=$ TRUE \\
\hline 4 & 0.284 & 4.000 & TRUE & $\begin{array}{l}\text { IF District }=\text { Richmond AND SF } 359=B \text { AND adt }>8598.00 \text { AND adt }<=28116.00 \\
\text { THEN SD }=\text { TRUE }\end{array}$ \\
\hline 6 & 0.398 & 4.000 & TRUE & $\begin{array}{l}\text { IF SF } 359=\text { C AND adt }<=3965.00 \text { AND } a d t>2314.00 \text { AND Age }<=42.00 \text { AND Pet } \\
\text { TK }<=6.00 \text { AND Pct } T K>2.00 \text { THEN SD }=\text { TRUE }\end{array}$ \\
\hline 3 & 0.333 & 2.000 & TRUE & If Pct $T K>17.00$ AND Age $<=19.00$ AND Age $>8.00$ THEN SD $=$ TRUE \\
\hline 2 & 0.250 & 1.000 & TRUE & IF SF $358=\mathrm{D}$ AND DK_CS $=\mathrm{D}$ THEN SD=TRUE \\
\hline 3 & 0.333 & 1.000 & TRUE & IF $a d t<=3965.00$ AND adt $>3955.00$ AND Age $<=43.00$ THEN SD $=$ TRUE \\
\hline 3 & 0.500 & 1.000 & TRUE & IF $a d t<=3436.00$ AND adt $>3402.00$ AND SF $359=C$ THEN SD $=$ TRUE \\
\hline 3 & 1.000 & 1.000 & TRUE & If $\mathrm{adt}<=487.00$ AND adt $>463.00$ AND Age $<=37.00$ THEN SD=TRUE \\
\hline
\end{tabular}

Figure 21: CN2 Rules for Concrete Deck (Rigid Overlay)

\begin{tabular}{|c|c|c|c|c|}
\hline $\begin{array}{l}\text { Rule } \\
\text { length }\end{array}$ & $\begin{array}{c}\text { Rule } \\
\text { quality }\end{array}$ & Coverage & $\begin{array}{l}\text { Predicted } \\
\text { class }\end{array}$ & Rule \\
\hline 2 & 0.001 & 8209.000 & FALSE & IF adt $>230.00$ AND Pct TK $<=13.00$ THEN SD $=$ FALSE \\
\hline 2 & 0.013 & 1222.000 & FALSE & IF Age $<=44.00$ AND DK_CS $=$ A THEN SD $=$ FALSE \\
\hline 2 & 0.086 & 116.000 & FALSE & IF DK_CS $=$ B AND Age $<=31.00$ THEN SD $=$ FALSE \\
\hline 2 & 0.148 & 17.000 & FALSE & IF Pct $T K>14.00$ AND Age $<=55.00$ THEN SD $=$ FALSE \\
\hline 1 & 0.152 & 7.000 & FALSE & IF SF $359=\mathrm{A}$ THEN SD $=$ FALSE \\
\hline 1 & 0.229 & 6.000 & FALSE & IF Age $>79.00$ THEN SD=FALSE \\
\hline 2 & 0.460 & 6.000 & FALSE & IF District=Richmond AND Age $>60.00$ THEN SD=FALSE \\
\hline 1 & 0.870 & 3.000 & FALSE & IF DK_CS $=C$ THEN SD $=$ FALSE \\
\hline 3 & 0.399 & 8.000 & TRUE & IF Age $>55.00$ AND adt $<=230.00$ AND Age $<=79.00$ THEN SD $=$ TRUE \\
\hline 2 & 0.416 & 5.000 & TRUE & IF DK_CS $=E$ AND Age $>2.00$ THEN SD $=$ TRUE \\
\hline 3 & 0.571 & 4.000 & TRUE & $\begin{array}{l}\text { IF Pct TK }>18.00 \text { AND Pct } T K<=19.00 \text { AND Age }<=60.00 \text { THEN } \\
\text { SD }=\text { TRUE }\end{array}$ \\
\hline 3 & 0.333 & 1.000 & TRUE & IF Age $>31.00$ AND SF $359=$ D AND Age $<=32.00$ THEN SD $=$ TRUE \\
\hline 2 & 0.027 & 74.000 & TRUE & IF Age $>44.00$ AND adt $<=4521.00$ THEN SD $=$ TRUE \\
\hline
\end{tabular}

Figure 22: CN2 Rules for Bare Concrete Deck (Coated Rebar)

\section{CONCLUSIONS}

$\underline{\text { Findings }}$

The following is a summarization of the findings of this research:

$>$ Classification methods can be used to develop a model to determine whether or not a bridge is structurally deficient based upon vector attributes. 
The performance of classification methods was fairly strong overall as there was not a huge difference in area under the ROC curve results.

Logistic regression, support vector machines, and the $\mathrm{CN} 2$ rule learner were the top three performing classifiers. Of the three, the $\mathrm{CN} 2$ rule learner is the recommended classification method due to its transparent nature and easy to understand rules.

The investigation of smart flags as an attribute, especially in painted steel girders (element 107), strengthened the classification analysis.

\section{Conclusion}

This study investigated the benefits of data mining and the utilization of classification methods to improve the ability to forecast when certain bridge types will become structurally deficient. The results of this study provide valuable insight to state agencies, as well as the public, on the condition and safety risks of bridges listed in the VDOT Pontis and National Bridge Inventory across the state of Virginia. Knowledge discovery was used in this analysis and all available resources were implemented in order achieve the objectives of this study. The findings of this study are significant and will be useful to VDOT engineers, bridge owners, bridge inspectors, and consulting engineers involved in the design and maintenance process.

The bridge elements studied were chosen specifically because of their abundance in Interstate and state owned bridges. The specific metrics chosen were age, location, ADT, and previously inspected condition states. These were investigated because of their direct correlation to the deterioration of bridges and their significance to asset value and user cost.

This study has produced significant results and has successfully utilized the VDOT Pontis and National Bridge Inventory in data mining, a seldom researched manner. The methods in 
which these results were produced can be modified by bridge type and the addition of bridge attributes can be implemented.

\section{$\underline{\text { Recommendations }}$}

The top performing classification methods were logistic regression, support vector machines, $k$-nearest neighbors, and $\mathrm{CN} 2$ rule learner, respectively. Because these methods performed so closely together, it is recommended that the $\mathrm{CN} 2$ rule learner is implemented when predicted bridge structural deficiency is desired. The reason for this is that it is one of the top performers in classification while maintaining an easy to understand method. Support vector machines and logistic regression, especially, are not as preferred due to their more complex nature. Results are calculated in what is much-like a black box and user's comprehension is not guaranteed. They can be difficult to understand and results produced may not make sense to the user. The CN2 rule learner produces clean and clear results using "if...then" statements, and is therefore the recommended classification method for users.

The Pontis analysis methods in this report on Virginia bridge data can be modified and implemented in other states already using the Pontis bridge management system. Depending on individual state's specific areas of maintenance interest, more attributes, such as bridge length or environmental conditions, could be investigated to determine their effects on classification. Additionally, classification could be extended to non-state owned bridges as well.

In order to facilitate statewide collaboration and cross-over amongst districts, it would be beneficial to implement a uniform database for storing information on maintenance actions across the state of Virginia. This way inspection records would be consistent across the state and electronic resources could be more readily utilized in bridge maintenance analyses. Additionally, if a more comprehensive criterion for bridge inspection existed, the discrepancy 
between inspector opinions would greatly be reduced. This would ensure inspection records to be more consistent, disparity between quantities would cease, and missing records could be reduced, and hopefully eliminated.

With time, more inspections take place and more data is collected. Following this report, it is suggested that methods are developed and incorporated to manage and analyze this data as it continues to pour in. Efficient means to handle inspection records, tables, and graphs is imperative to minimize man power and implement more sophisticated statistical software packages. 


\section{REFERENCES}

AASHTO. (2005). Pontis Technical Manual.

AASHTO. (2005). Pontis User Manual.

AASHTO. (2007). Maintenance Manual for Roadways and Bridges.

AASHTO. (2011). Manual For Bridge Evaluation.

Bektas, Basak Aldemir, Alicia Carriquiry, and Omar Smadi. (2012). "Using classification trees for predicting national bridge inventory condition ratings." Journal of Infrastructure Systems 19.4 (2012): 425-433.

Bolukbasi, Melik, Jamshid Mohammadi, and David Arditi. (2004). "Estimating the future condition of highway bridge components using national bridge inventory data." Practice Periodical on Structural Design and Construction 9.1 (2004): 16-25.

Bramer, Max. (2002). "Pre-pruning classification trees to reduce overfitting in noisy domains." Intelligent Data Engineering and Automated Learning—IDEAL 2002. Springer Berlin Heidelberg: 7-12.

Chase, Steven B., Edgar P. Small, and Chris Nutakor. (1999). "An in-depth analysis of the national bridge inventory database utilizing data mining, GIS and advanced statistical methods." Transportation Research Circular 498 (1999): 1-17.

Clark, Peter, and Tim Niblett. (1989). "The CN2 induction algorithm." Machine learning3.4: 261-283.

Demšar, Janez, Blaz Zupan, Gregor Leban, and Tomaz Curk. Orange: From experimental machine learning to interactive data mining. Springer Berlin Heidelberg, 2004. 
Dreiseitl, Stephan, and Lucila Ohno-Machado. (2002). "Logistic regression and artificial neural network classification models: a methodology review." Journal of biomedical informatics 35.5: 352-359.

Dzeroski, Sašo, Bojan Cestnik, and Igor Petrovski. (1993). "Using the m-estimate in rule induction." Journal of Computing and Information Technology 1.1: 37-46.

Encyclopedia Britannica. (2014). "Nomograph (mathematics)." Encyclopedia Britannica Online. <http://www.britannica.com/EBchecked/topic/417428/nomograph>.

FHWA - FAPG 23 CFR 650C, National Bridge Inspection Standards. (1994). <http://www.fhwa.dot.gov/legsregs/directives/fapg/cfr0650c.htm>.

FHWA. (1995). Recording and Coding Guide for the Structure Inventory and Appraisal of the Nation's Bridges

Goldberger, J., Roweis, S., Hinton, G., \& Salakhutdinov, R. (2004). “Neighbourhood components analysis.”

Hand, David J., Heikki Mannila, and Padhraic Smyth. Principles of Data Mining. Cambridge, Mass.: MIT, 2001. Print.

Hanley, James A., and Barbara J. McNeil. (1982). "The meaning and use of the area under a receiver operating characteristic (ROC) curve." Radiology 143.1: 29-36.

Hearn, George. (2010). Framework for a National Database System for Maintenance Actions on Highway Bridges. Vol. 668. Transportation Research Board, 2010.

Hsu, Chih-Wei, Chih-Chung Chang, and Chih-Jen Lin. (2003). "A practical guide to support vector classification."

Jain, Anil K., Robert P. W. Duin, and Jianchang Mao. (2000). "Statistical pattern recognition: A review." Pattern Analysis and Machine Intelligence, IEEE Transactions on 22.1: 4-37. 
Johnston, Jamie. (2013). "Exploratory Investigation of Legacy Bridge Databases in Virginia." http://search.lib.virginia.edu/catalog/libra-oa:2901

Khan, Maleq, Qin Ding, and William Perrizo. (2002)."k-nearest neighbor classification on spatial data streams using P-trees." Advances in Knowledge Discovery and Data Mining. Springer Berlin Heidelberg: 517-528.

Langel, Matti, and Yves Tillé. (2013). "Variance estimation of the Gini index: revisiting a result several times published." Journal of the Royal Statistical Society: Series A (Statistics in Society) 176.2: 521-540.

Lavrač, Nada, Branko Kavsek, Peter Flach, and Ljupčo Todorovski. (2004). "Subgroup discovery with CN2-SD." The Journal of Machine Learning Research 5: 153-188.

Lewis, David D. (1998). "Naive (Bayes) at forty: The independence assumption in information retrieval." Machine learning: ECML-98. Springer Berlin Heidelberg: 4-15.

Loh, Wei-Yin. (2011). "Classification and regression trees." Wiley Interdisciplinary Reviews: Data Mining and Knowledge Discovery 1.1: 14-23.

Loh, Wei-Yin, and Yu-Shan Shih. (1997). "Split selection methods for classification trees." Statistica sinica 7.4: 815-840.

Madanat, Samer, Rabi Mishalani, and Wan Hashim Wan Ibrahim. (1995). "Estimation of infrastructure transition probabilities from condition rating data." Journal of infrastructure systems 1.2: 120-125.

Michalski, Ryszard S., Igor Mozetic, Jiarong Hong, and Nada Lavrač. (1986). "The multi purpose incremental learning system AQ15 and its testing application to three medical domains." Proc. AAAI 1986: 1-041. 
Mitchell, Tom. (2010). Generative and Discriminative Classifiers: Naïve Bayes and Logistic Regression. Machine Learning.

National Transportation Safety Board. "Highway Accident Report." Accident Investigations. 1970. <https://www.ntsb.gov/investigations/summary/HAR7101.htm>.

Orange. (2014). <http://docs.orange.biolab.si/widgets/rst/index.html>

Ottenbacher, Kenneth J., Richard T. Linn, Pamela M. Smith, Sandra B. Illig, Melodee Mancuso, and Carl V. Granger. (2004). "Comparison of logistic regression and neural network analysis applied to predicting living setting after hip fracture." Annals of epidemiology 14.8: 551-559.

Platt, John C. (1999). "Probabilistic outputs for support vector machines and comparisons to regularized likelihood methods." Advances in large margin classifiers.

Robert, W. E., Marshall, A. R., Shepard, R., \& Aldayuz, J. (2003). The Pontis bridge management system: State-of-the-practice in implementation and development. Proceedings of the 9th International Bridge Management Conference, (pp. 49-60)

Rish, Irina. (2001). "An empirical study of the naive Bayes classifier." IJCAI 2001 workshop on empirical methods in artificial intelligence. Vol. 3. No. 22.

Sayad, Saed. (2012). "Logistic Regression." An Introduction to Data Mining. <http://www.saedsayad.com/logistic_regression.htm>.

Shepard, Richard W., and Michael B. Johnson. (2001). "California bridge health index: a diagnostic tool to maximize bridge longevity, investment." TR News 215.

Small, E. P., Philbin, T., Fraher, M., \& Romack, G. P. (1999). Current status of bridge management system implementation in the United States. 8th Internation Bridge Management Conference, (pp. A-1/1-16). 
Strobl, Carolin, Anne-Laure Boulesteix, and Thomas Augustin. (2007). "Unbiased split selection for classification trees based on the Gini index." Computational Statistics \& Data Analysis 52.1: 483-501.

"Support Vector Machines (SVM)." (2014). StatSoft Inc. Statistica, Jan. 2014. <http://www.statsoft.com/Textbook/Support-Vector-Machines >.

"Support Vector Machines (SVM)." (2014). The MathWorks, Inc. MATLAB \& Simulink, Jan. 2014. <http://www.mathworks.com/help/stats/support-vector-machines-svm.html>.

Swets, John A. (2014). Signal detection theory and ROC analysis in psychology and diagnostics: Collected papers. Psychology Press, 2014.

Thompson, Paul D., Edgar P. Small, Michael Johnson, and Allen R. Marshall. (1998). "The Pontis bridge management system." Structural Engineering International 8.4: 303-308.

Tu, Jack V. (1996). "Advantages and disadvantages of using artificial neural networks versus logistic regression for predicting medical outcomes." Journal of clinical epidemiology 49.11: 1225-1231.

Tukey, John W. (1977). Exploratory Data Analysis. Addison-Wesley

Umano, Motohide, Hirotaka Okamoto, Itsuo Hatono, Hirojuki Tamura, Fumio Kawachi, Sukehisa Umedzu, and Junichi Kinoshita. (1994). "Fuzzy decision trees by fuzzy ID3 algorithm and its application to diagnosis systems." Fuzzy Systems, 1994. IEEE World Congress on Computational Intelligence., Proceedings of the Third IEEE Conference.

Vapnik, Vladimir N. (1999). "An overview of statistical learning theory." Neural Networks, IEEE Transactions on 10.5: 988-999.

VDOT. (2007). Pontis Element Data Collection Manual. 
Weinberger, Kilian Q., John Blitzer, and Lawrence K. Saul. (2005). "Distance metric learning for large margin nearest neighbor classification." Advances in neural information processing systems. 2005.

Widodo, Achmad, and Bo-Suk Yang. (2007). "Support vector machine in machine condition monitoring and fault diagnosis." Mechanical Systems and Signal Processing 21.6: 2560.

Wu, Nien-Chun, and Stephen Chase. An Exploratory Data Analysis of National Bridge Inventory. No. UVA-2009-03. 2010.

Zaiontz, Charles. (2014). "Basic Concepts of Logistic Regression." Real Statistics Using Excel. <http://www.real-statistics.com/logistic-regression/basic-concepts-logistic-regression/>. 


\section{APPENDIX A - ELEMENT CODES AND DESCRIPTIONS}

Derived from the Pontis Element Data Collection Manual (VDOT, 2007) 


\begin{tabular}{|l|l|}
\hline Code & Element Description (V denotes Virginia element) \\
\hline 012 & Concrete Deck - Bare - with Uncoated Reinforcement \\
\hline 013 & Concrete Deck - with AC Overlay - without Membrane \\
\hline 014 & Concrete Deck - with AC Overlay - with Membrane \\
\hline 018 & Concrete Deck - Thin Overlay (less than 1") - no AC Overlay \\
\hline 022 & Concrete Deck - Rigid Overlay (greater than 1") - no AC Overlay \\
\hline 026 & Concrete Deck - Bare - with Coated Reinforcement \\
\hline 027 & Concrete Deck - with Cathodic Protection \\
\hline 028 & Steel Deck - Open Grid \\
\hline 029 & Steel Deck - Concrete Filled Grid \\
\hline 030 & Metal Deck - Corrugated/Orthotropic, Etc \\
\hline 031 & Timber Deck \\
\hline 032 & Timber Deck - with asphaltic concrete (AC) Overlay \\
\hline 038 & Concrete Slab - Bare - with Uncoated Reinforcement \\
\hline 039 & Concrete Slab - with AC Overlay - without Membrane \\
\hline 040 & Concrete Slab - with AC Overlay - with Membrane \\
\hline 044 & Concrete Slab - Thin Overlay (less than 1") - no AC Overlay \\
\hline 048 & Concrete Slab - Rigid Overlay (greater than 1") - no AC Overlay \\
\hline 052 & Concrete Slab - Bare - with Coated Reinforcement \\
\hline 053 & Concrete Slab - with Cathodic Protection \\
\hline 054 & Timber Slab \\
\hline 055 & Timber Slab - with asphaltic concrete (AC) Overlay \\
\hline 092 & V Reinforced Concrete Sidewalk \\
\hline 094 & V Timber Sidewalk \\
\hline 098 & V Steel Sidewalk, Open Grid - Coated \\
\hline 101 & Steel Closed Web/Box Girder - Uncoated \\
\hline 102 & Steel Closed Web/Box Girder - Coated \\
\hline 104 & P/S Concrete Voided and Unvoided Closed Web/Box Girder \\
\hline 105 & Reinforced Concrete Voided and Unvoided Closed Web/Box Girder \\
\hline 106 & Steel Open Girder - Uncoated \\
\hline 107 & Steel Open Girder - Coated \\
\hline 108 & V Steel Open Girder with Timber Deck - Coated and Uncoated \\
\hline 109 & P/S Concrete Open Girder \\
\hline 110 & Reinforced Concrete Open Girder \\
\hline 111 & Timber Open Girder \\
\hline 112 & Steel Stringer - Uncoated \\
\hline 113 & Steel Stringer - Coated \\
\hline 115 & P/S Concrete Stringer \\
\hline 116 & Reinforced Concrete Stringer \\
\hline 117 & Timber Stringer \\
\hline 120 & Steel Bottom Chord of Through Truss - Uncoated \\
\hline 121 & Steel Bottom Chord of Through Truss - Coated \\
\hline 125 & Steel Through Truss excluding bottom chord - Uncoated \\
\hline
\end{tabular}




\begin{tabular}{|l|l|}
\hline 126 & Steel Through Truss excluding bottom chord - Coated \\
\hline 130 & Steel Deck Truss - Uncoated \\
\hline 131 & Steel Deck Truss - Coated \\
\hline 135 & Timber Truss or Arch \\
\hline 140 & Steel Arch - Uncoated \\
\hline 141 & Steel Arch - Coated \\
\hline 143 & P/S Concrete Arch \\
\hline 144 & Reinforced Concrete Arch \\
\hline 145 & Other Material Arch \\
\hline 146 & Steel Cable - Uncoated (not embedded in concrete) \\
\hline 147 & Steel Cable (not embedded in concrete) - Coated \\
\hline 151 & Steel Floor Beam - Uncoated \\
\hline 152 & Steel Floor Beam - Coated \\
\hline 154 & P/S Concrete Floor Beam \\
\hline 155 & Reinforced Concrete Floor Beam \\
\hline 156 & Timber Floor Beam \\
\hline 160 & Steel Pin and/or Pin \& Hanger Assembly - Uncoated \\
\hline 161 & Steel Pin and/or Pin \& Hanger Assembly - Coated \\
\hline 201 & Steel Column or Pile Extension - Uncoated \\
\hline 202 & Steel Column or Pile Extension - Coated \\
\hline 204 & P/S Concrete Column or Pile Extension \\
\hline 205 & Reinforced Concrete Column or Pile Extension \\
\hline 206 & Timber Column or Pile Extension \\
\hline 210 & Reinforced Concrete Pier Wall \\
\hline 211 & Other Material Pier Wall \\
\hline 215 & Reinforced Concrete Abutment \\
\hline 216 & Timber Abutment \\
\hline 217 & Other Material Abutment \\
\hline 220 & Reinforced Concrete Submerged Pile Cap/Footing \\
\hline 225 & Steel Submerged Pile \\
\hline 226 & P/S Concrete Submerged Pile \\
\hline 227 & Reinforced Concrete Submerged Pile \\
\hline 228 & Timber Submerged Pile \\
\hline 230 & Steel Pier Cap - Uncoated \\
\hline 231 & Steel Pier Cap - Coated \\
\hline 233 & P/S Concrete Pier Cap \\
\hline 234 & Reinforced Concrete Pier Cap \\
\hline 235 & Timber Pier Cap \\
\hline 240 & Metal Culvert \\
\hline 241 & Concrete Culvert \\
\hline 242 & Timber Culvert \\
\hline 243 & Other Culvert \\
\hline 285 & V Slope - Protected \\
\hline & \\
\hline
\end{tabular}




\begin{tabular}{|l|l|}
\hline 286 & V Slope - Unprotected \\
\hline 295 & V Reinforced Concrete Wingwalls \\
\hline 296 & V Timber Wingwalls \\
\hline 297 & V Other Material Wingwalls \\
\hline 298 & Smart Flag - Culvert Endwall/Headwall \\
\hline 298 & V Smart Flag - Culvert Endwall/Headwall \\
\hline 299 & V Smart Flag - Culvert Wingwall \\
\hline 300 & Strip Seal Expansion Joint \\
\hline 301 & Pourable Joint Seal \\
\hline 302 & Compression Joint Seal \\
\hline 303 & Assembly Joint/Seal \\
\hline 304 & Open Expansion Joint \\
\hline 310 & Elastomeric Bearing \\
\hline 311 & Moveable Bearing (Roller, sliding, etc.) \\
\hline 312 & Enclosed/Concealed Bearing or Bearing System \\
\hline 313 & Fixed Bearing \\
\hline 314 & Pot Bearing \\
\hline 315 & Disk Bearing \\
\hline 320 & Prestressed Concrete Approach Slab \\
\hline 321 & Reinforced Concrete Approach Slab \\
\hline 330 & Metal Bridge Railing - Uncoated \\
\hline 331 & Reinforced Concrete Bridge Railing \\
\hline 332 & Timber Bridge Railing \\
\hline 334 & Metal Bridge Railing - Coated \\
\hline 356 & Smart Flag - Steel Fatigue \\
\hline 357 & Smart Flag - Pack Rust \\
\hline 358 & Smart Flag - Deck Cracking \\
\hline 359 & Smart Flag - Soffit of Concrete \\
\hline 360 & Smart Flag - Settlement \\
\hline 361 & Smart Flag - Scour \\
\hline 362 & Smart Flag - Traffic Impact Damage \\
\hline 363 & Smart Flag - Section Loss \\
\hline 444 & V Mechanically Stabilized Earth - Abutment \\
\hline 701 & V Smart Flag - Utilities \\
\hline 702 & V Smart Flag - Drains \\
\hline 703 & V Smart Flag - Lighting \\
\hline 704 & V Smart Flag - Roadway Over Culverts \\
\hline 706 & V Smart Flag - Soffit of Overhang of Concrete \\
\hline 707 & V Smart Flag - Soffit of Concrete \\
\hline 708 & V Smart Flag - Debris in Channel \\
\hline 709 & V Smart Flag - Replacement \\
\hline 710 & V Smart Flag - Deck Replacement \\
\hline 738 & Concrete Slab - Covered with Fill \\
\hline & \\
\hline
\end{tabular}




\section{APPENDIX B - NOMOGRAPHS OF LOGISTIC REGRESSION RESULTS}

Derived from the Orange Data Mining Software 


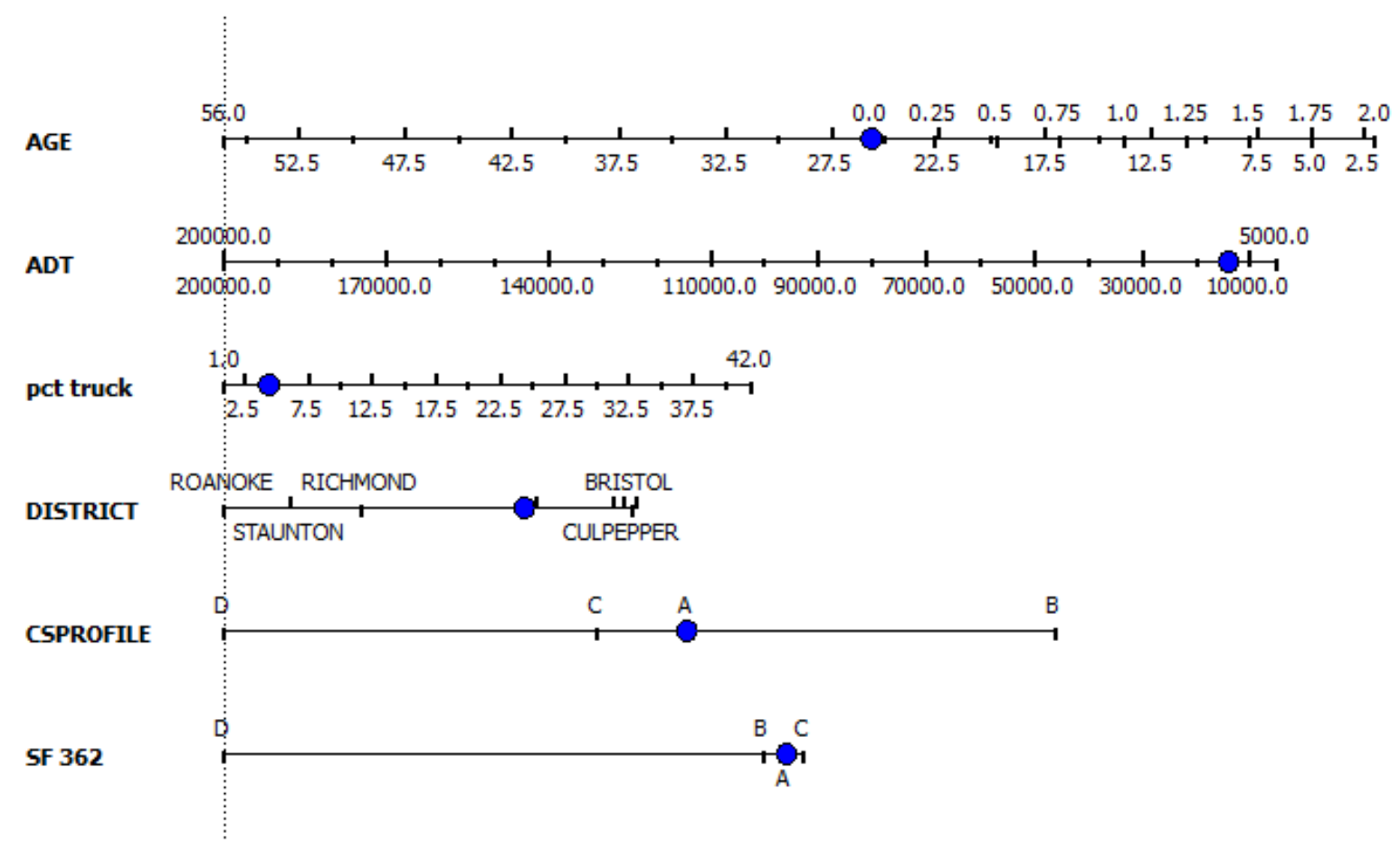

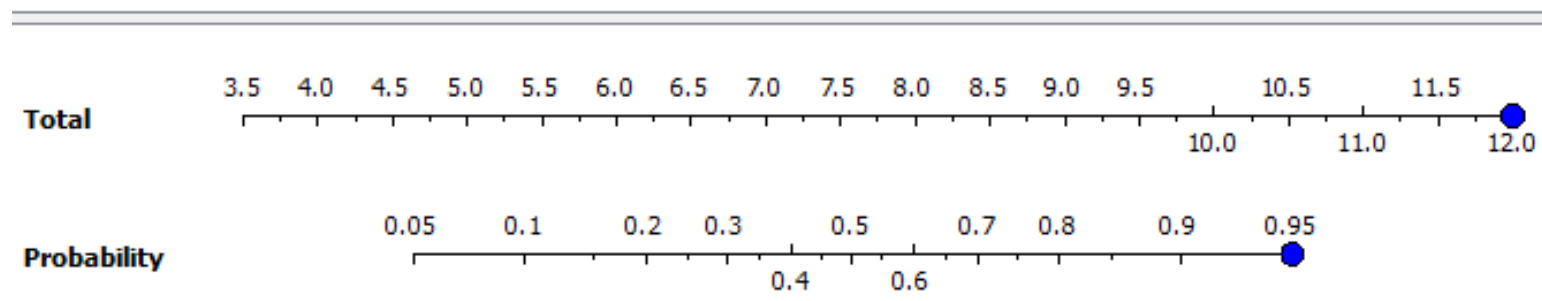

Figure B - 1: Nomograph of Prestressed Concrete Girders 


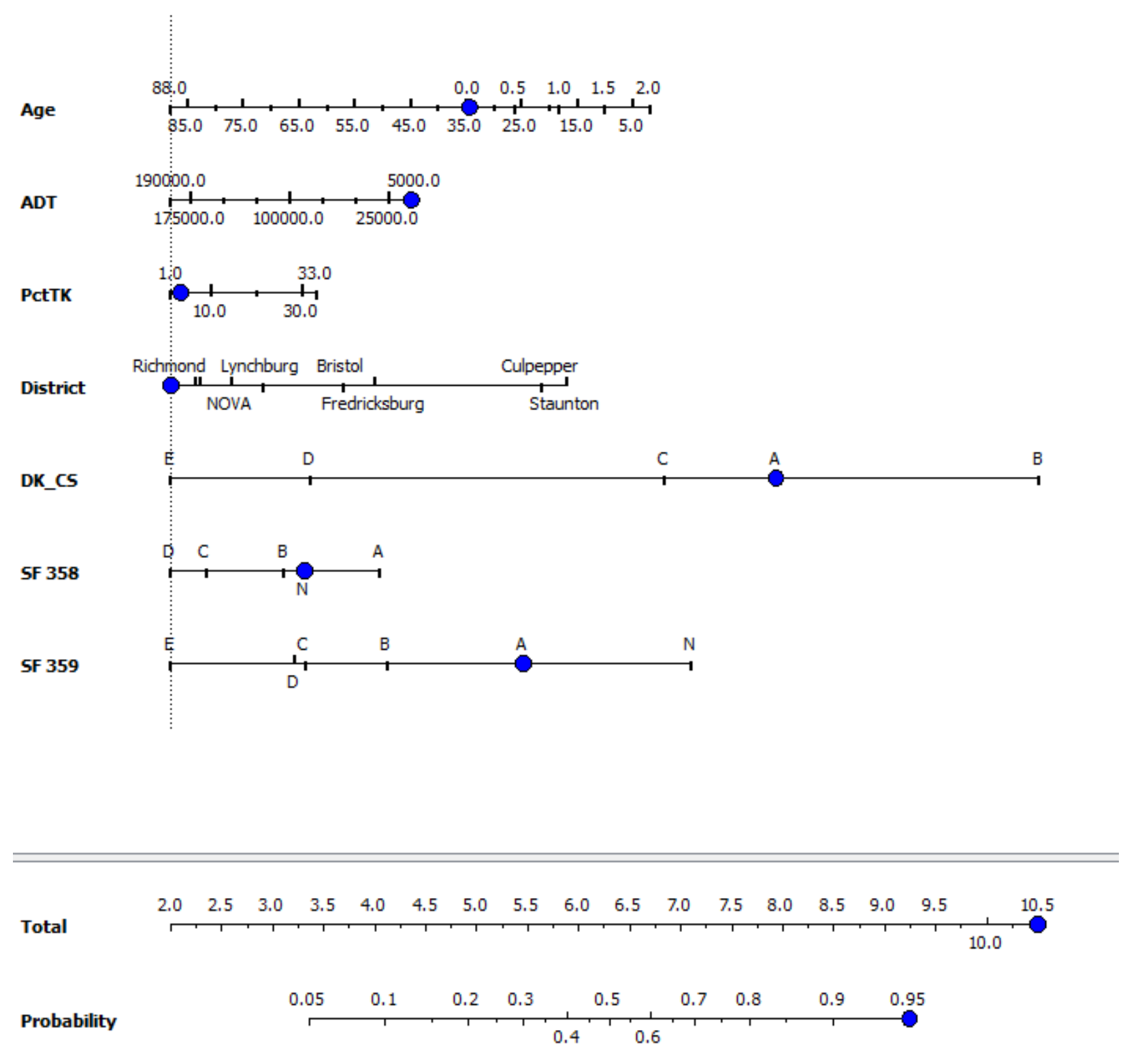

Figure B - 2: Nomograph of Bare Concrete Deck (Uncoated Rebar) 

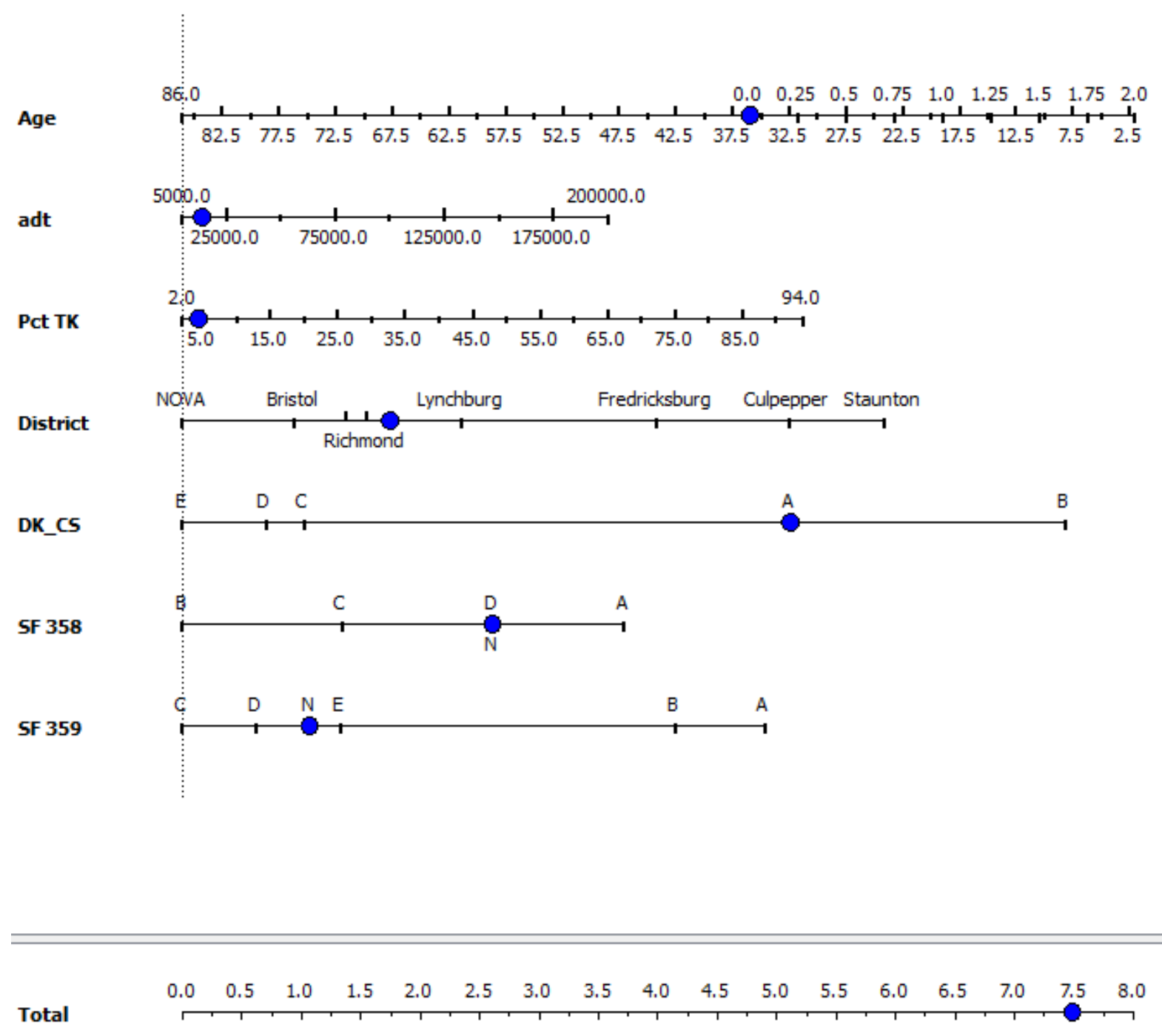

Probability

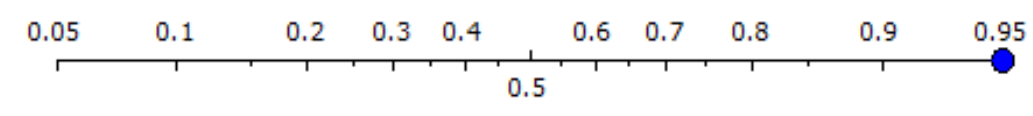

Figure B - 3: Nomograph of Concrete Deck (Thin Overlay) 


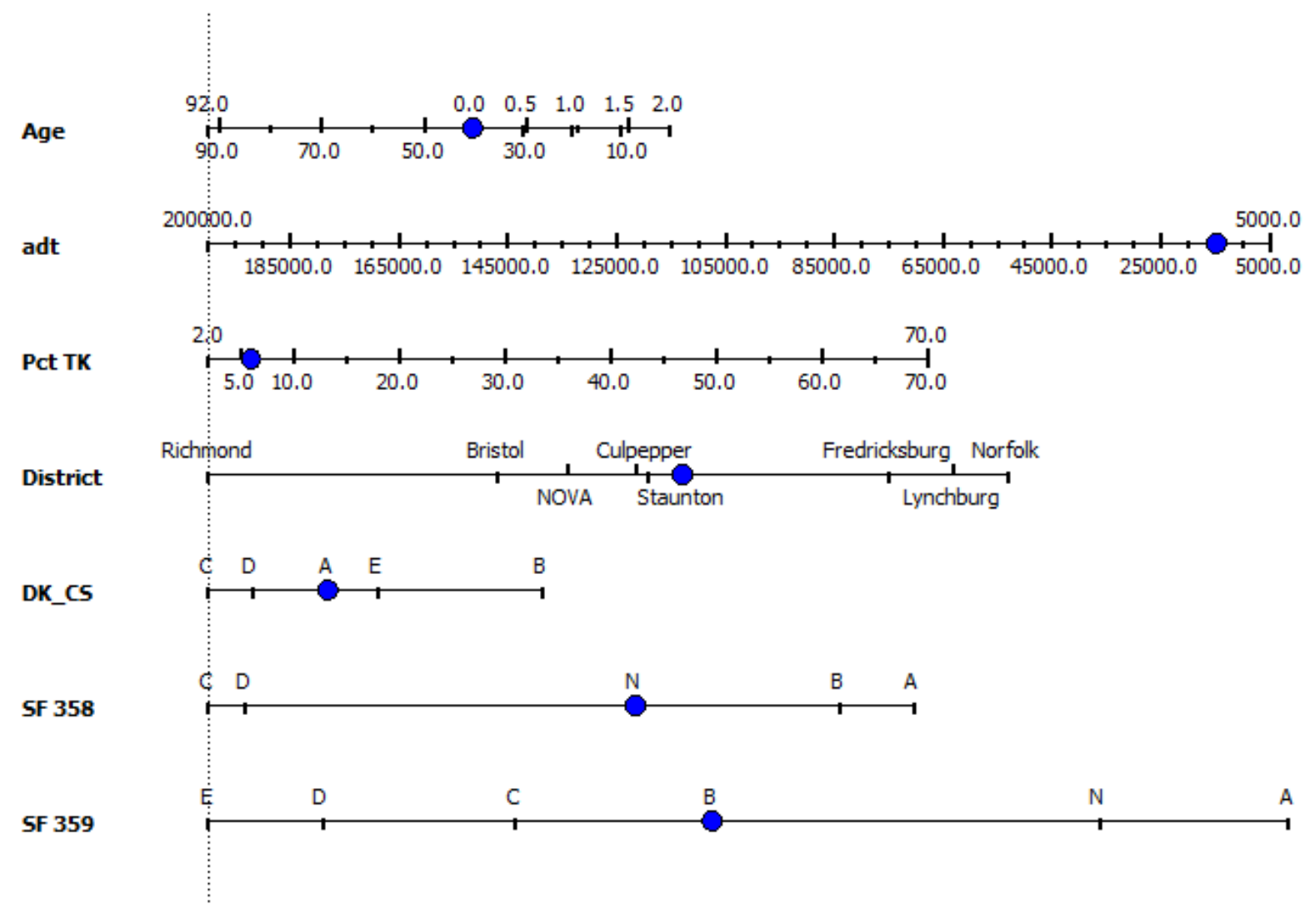

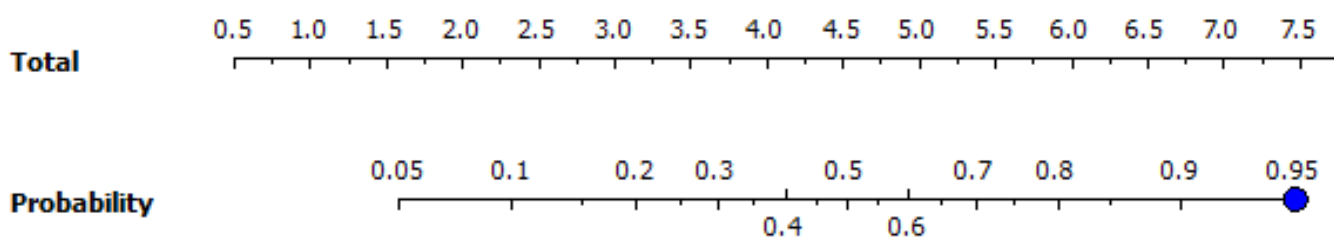

Figure B - 4: Nomograph of Concrete Deck (Rigid Overlay) 


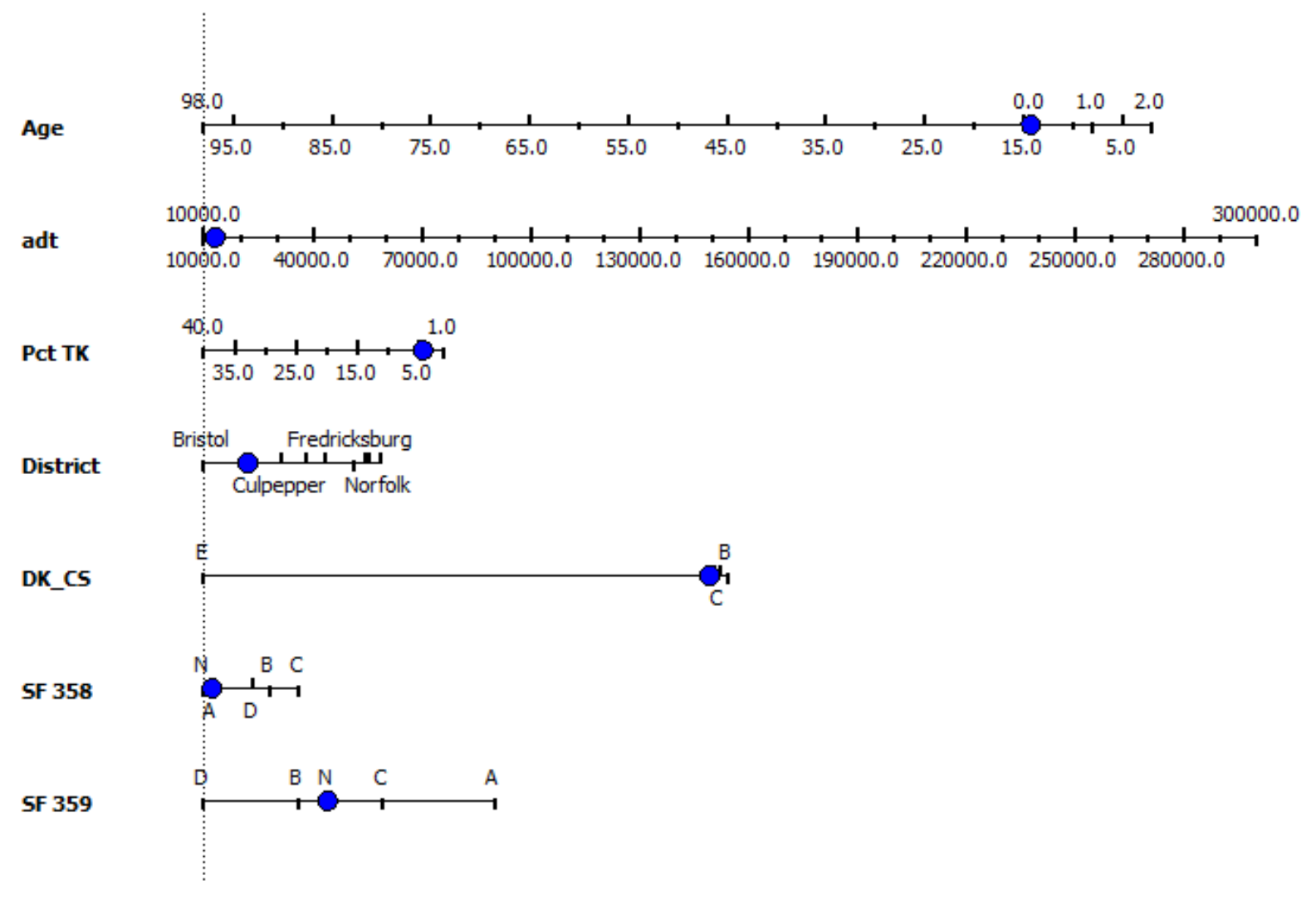

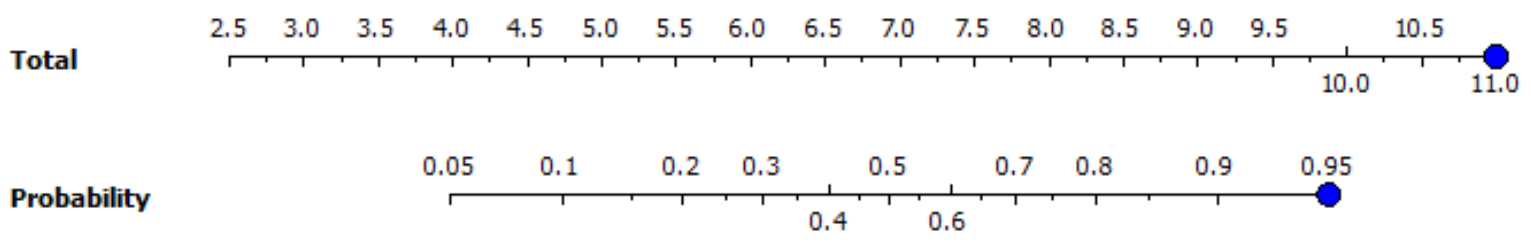

Figure B - 5: Nomograph of Bare Concrete Deck (Coated Rebar) 